\title{
The linguistic landscape of Nuuk, Greenland
}

\begin{abstract}
The purpose of this article is to present and analyse public and private signs in the linguistic landscape of Nuuk, the capital of Greenland. Nuuk is a trilingual environment including the indigenous language (West Greenlandic), the former colonial language (Danish), and the global language (English). West Greenlandic is a somewhat unusual case among indigenous languages in colonial and postcolonial settings because it is a statutory national language with a vigorous use. Our analysis examines the use of West Greenlandic, Danish, and English from the theoretical perspective of centre vs. periphery, devoting attention to the primary audiences (local vs. international) and chief functions (informational vs. symbolic) of the signs. As the first investigation into the Greenlandic linguistic landscape, our analysis can contribute to research on signs in urban multilingual indigenous language settings.
\end{abstract}

Keywords: linguistic landscape, Greenlandic, Danish, Nuuk, Greenland, signs, multilingual, urban, minority, indigenous

\section{Introduction}

The purpose of our study is to analyse public and private signs in the linguistic landscape of Nuuk, the capital of Greenland. Scholarly enquiry into the linguistic landscape seeks to ascertain the practices and ideologies relating to the language appearing in public spaces. The public spaces included in this type of analysis consist of official signs (e.g. traffic signs, street names, government notices), private signs (e.g. shop names, private business signs, personal ads), graffiti, food packaging, notes, discarded items, and moving signs on buses or t-shirts (see e.g. see Gorter, 2006; Shohamy \& Gorter, 2009; Jaworski \& Thurlow, 2010). The dynamic, constantly mediated multimodal linguistic landscape gives space its meaning and interacts with the built environment (Moriarty, 2014a). 


\subsection{Greenlandic language policy and sociolinguistic background}

West Greenlandic (also called Kalaallisut or Greenlandic) is the indigenous Inuit language of Greenland and is spoken by approximately 50,000 people in Greenland and Denmark. It is an Eskimo-Aleut language and closely related to Inuktitut in Canada. Greenland has been under the Scandinavian sphere of influence since the Middle Ages, and became a Danish colony in the 1600s. From this period onwards, West Greenlandic speakers have been in constant contact with Danish, as the language of centuries-long colonial rule. From the beginning of the 1900s until the 1950s, West Greenlandic and Danish were both widely used in educational settings, and West Greenlandic was actively used in literary and poetic contexts (Fredriksen \& Olsen, 2017: 5). From 1959 onwards, West Greenlandic-medium education was eclipsed by Danish (Fredriksen \& Olsen, 2017: 5). This situation changed in 1979 , when Greenland ceased to be a Danish colony and achieved Home Rule. The Home Rule Act granted official status to West Greenlandic, though alongside Danish. Greenland achieved a greater level of political autonomy in 2009, when Home Rule was replaced with Self Rule. According to Article 20 of the Self Rule Act, West Greenlandic is the only official language, though Danish can be used in administration. There is a thriving standardized language based on West Greenlandic. In 2012, an amendment to the language law was made whereby official written documents such as contracts, as well as advertisements and signs produce by both the authorities and private companies, must be written in West Greenlandic, with Danish, English and other foreign languages allowed in a supplementary position. The amendment does not apply to imported goods, instructions on packaging, slogans, company names, or the like. A particular entity can apply for an exemption to this if they want to use Danish only, but 
they are required to pay for the associated costs. See Sermitsiaq (2012) for details of the 2012 amendment.

Most of the population of Greenland is comprised of indigenous Inuits. Danes who live on the island constitute around $12 \%$ of the population (Central Intelligence Agency, 2017). There are also some foreign nationals of other backgrounds, with the largest groups comprising Thais, Filipinos, and Icelanders (Kleemann, 2018: 8). Conversely, for the past 40 years Greenland has had net emigration; as of 2016, there were over 17,000 Greenlanders living in Denmark, which is a considerable number considering that the overall population of Greenland is approximately 56,000 (Kleemann, 2018: 5-8).

Apart from Fredriksen and Olsen (2017), who describe recent general tendencies with respect to Greenlandic language policy and use, there are no large-scale quantitative or qualitative sociolinguistic studies on Greenland in the 21 st century, and as such it is not possible to supply precise information in this respect. As of the turn of the millennium, around $70 \%$ of Greenlanders self-reported as being West Greenlandic speaking, $15 \%$ selfreported as bilingual, and 15\% self-reported as being solely Danish speaking (Langgård, 2001: 3). The subsequent two decades have seen a clear trajectory towards greater levels of bilingualism among first-language West Greenlandic speakers: the number of totally bilingual speakers and first-language West Greenlandic speakers with good command of Danish has risen, while the number of monolingual West Greenlandic speakers has gone down; by contrast, the number of first-language Danish speakers with good knowledge of West Greenlandic has remained stable in this period (Fredriksen and Olsen, 2017: 2324). English is a widespread third language and has been growing in prominence. In practice, at present the number of native West Greenlandic speakers with fluent command 
of Danish appears to be extremely high, but, as mentioned above, there are no official statistics to support this (the Greenlandic government does not collect data on firstlanguage, second-language, or preferred language use; see www.stat.gl).

With respect to educational language policy, the disparities between the status of West Greenlandic and Danish are particularly prominent. In comprehensive (i.e. primary and lower secondary) schools, Greenlandic is typically the medium of instruction, but Danish is taught as a second language from the first grade onwards, and English is also introduced from the earliest grades (Kleemann, 2018: 13). West Greenlandic teaching materials and methods are regarded as relatively poor in contrast to those available for Danish and English, and this can contribute to a weakening in perception of the prestige of West Greenlandic vis-à-vis these globally more dominant languages at an early age (Fredriksen \& Olsen, 2017: 14-15). Strikingly, upper secondary education (the equivalent of sixth-form college in the UK), which is optional, is all purely Danish-medium, with no opportunity for West Greenlandic instruction. As such, anyone desiring to gain an upper secondary school diploma in Greenland must do so through the medium of Danish, which has the concomitant effect of lowering the prestige of West Greenlandic and encourages young people to prioritize Danish in an effort to access more advanced education (Fredriksen \& Olsen, 2017). This is perhaps reflected in the fact that Greenland has relatively low levels of upper secondary school attainment: among the 18-25 year old population, only approximately $40 \%$ have completed high school or vocational education; similarly, only approximately half of all 25-64 year-old Greenlanders have education beyond the lower secondary level (Kleemann, 2018: 13-14). However, in recent years university education in West Greenlandic has become an option, with some courses at the University of Greenland offered in the language, such as teacher training and translation 
studies. Currently, English is taught in some schools from the first grade onwards, like Danish (Fredriksen \& Olsen, 2017: 6). There are large generational differences in this respect: in some cases, Greenlanders cannot speak Danish and have never received instruction in the language, while conversely others have never received instruction in West Greenlandic. Similarly, some have never learned to write West Greenlandic, though they can speak it, while others have never learned to write Danish (Fredriksen \& Olsen, 2017: 8). This heterogeneity can make it difficult to apply language policies evenly for all of Greenland's inhabitants. Greenland has a 100\% literacy rate overall, but this is distributed between West Greenlandic and Danish, rather than the whole population being able to read West Greenlandic. It should be noted, however, that within the Arctic region Greenland is seen to have the 'strongest language policies of any Arctic country and also the most robust indigenous language usage' (Grenoble, 2015: 16).

The Greenlandic workforce has large fishing and public administration sectors, as well as some construction, mining, seafood processing, agriculture, and a growing tourism industry (Kleemann, 2018: 23). Most of the Danes living in Greenland work as tradesmen, academics, teachers, and administrators. Although tourism has been a key priority for Greenland since 1991, the sector has shown slow growth due to its remote location, high transport costs, and extreme climate (Kaae, 2006). The Greenlandic industrial sector is dominated by a relatively small number of large publicly owned companies, such as Royal Arctic Line (a shipping company), Tele Greenland (telecommunications), and Royal Greenland (fishing) (Kleemann, 2018: 24). In workplaces, while West Greenlandic is the only language with official status, in practice Danish is a requirement, as Danish speakers are more likely to be monolingual and everyone is expected to switch to Danish if a Danish speaker is present. Moreover, 
technical and profession-specific language has not had the ability to develop given the historical and continuing dominance of Danish, which results in West Greenlandic speakers (as in the case of secondary education) being put in a position where their knowledge of Danish is a de-facto prerequisite for professional development and advancement at the expense of West Greenlandic (Fredriksen \& Olsen, 2017: 9). As in the case of professional circles more broadly, the public sector is centred around Danish (Fredriksen \& Olsen, 2017: 10). However, in some cases West Greenlandic is employed in the public sector: for example, political campaigns, parliamentary debates, and related activities are often conducted in West Greenlandic, as are the TV and radio broadcasts of and commentary on these activities.

With respect to print and digital media, the situation is similar in that Danish and West Greenlandic likewise both feature but have somewhat unequal roles. The country's main newspaper, Sermitsiaq, is published in print and online in a bilingual West Greenlandic-Danish edition, but the languages are unequally distributed, as the articles are all initially written in Danish and then translated into West Greenlandic. This has the effect of promoting Danish-influenced West Greenlandic language structures, which are sometimes misleading or incorrect, as well as of encouraging readers to prioritize Danish because the online articles appear first in that language, with the West Greenlandic versions appearing only after the news is already somewhat dated (Fredriksen \& Olsen, 2017: 12). However, the amount of West Greenlandic-language content on the Sermitsiaq website has gone up since 2010 , from approximately $60 \%$ to approximately $80 \%$ (Fredriksen \& Olsen, 2017: 13). Moreover, significant resources are invested in ensuring that Danish-speaking monolinguals have access to official Greenlandic media, as all West 
Greenlandic-language TV content is subtitled in Danish, and all radio and print material is produced in a bilingual format (Fredriksen \& Olsen, 2017: 13).

\subsection{Short history of Nuuk}

Nuuk is the capital of Greenland and its largest city. The area around Nuuk has been continuously settled by the local Inuit population since at least the medieval period. The city was officially founded in 1728 by the Dano-Norwegian official Claus Paarss, who was the governor of Greenland at that time, and called by the Danish name of Godthåb 'Good Hope'. It remained a relatively small settlement until the 1960s, which saw the beginnings of a widespread urbanization drive in Greenland initiated by the colonial Danish authorities. At this time, the Danish government moved large numbers of rural residents to the capital, creating the first truly urban Greenlandic environment, which in turn led to rapid growth and a dramatic impact on the traditional way of life (Grydehoj, 2014; see also Bjerregaard, Curtis, \& the Greenland Population Survey, 2002). Godthåb was officially renamed Nuuk in 1979, coinciding with Greenland being granted Home Rule. As of January 2018, Nuuk had approximately 17,800 inhabitants (Kleemann, 2018: 37), over a third of the total population of Greenland.

\subsection{Theoretical framework and research questions}

Theoretically, our study is based primarily on the notions of centre and periphery. In minority language contexts there is a constantly negotiated dynamic process of centralizing and peripheralizing norms and ideologies between the majority and minority language(s) (Kelly-Holmes, 2013; Kelly-Holmes \& Pietikäinen, 2013; Pietikäinen, 2013; Pietikäinen, Jaffe, Kelly-Holmes, \& Coupland, 2016; also Grydehoj, 2014, 2016). The 
centre is occupied by languages that are perceived as dominant and advanced, and associated with political, economic, and trade power. The periphery is the opposite, associated with languages lacking in prestige or official support. Globalization complicates the local dynamics between languages by bringing English into the picture (Wright, 2004: 136-156).

From the perspective of this theoretical framework of centre vs. periphery, our study will explore the following questions: How central is West Greenlandic, Greenland's only official language, vis-à-vis Danish, the former colonial language, and English, the global language, in Nuuk's linguistic landscape? How does the primary audience for the sign (local or international) relate to the choice of central language, or languages? To what extent does the selection of West Greenlandic, Danish, and/or English on a given sign reflect an informational function as opposed to a symbolic one? Can a language play both an informational and a symbolic role simultaneously? We employ the notions of centre and periphery first and foremost with respect to the positioning of the text and choice of language on the signs examined. We then use these findings to interrogate the relative status of the relevant languages (whether central or peripheral) in society as reflected in the linguistic landscape.

Our study fits in with a number of recent analyses of the linguistic landscape in minority language and multilingual settings, particularly in Europe. These include specific examination of signs appearing in various contexts examined in our study. For example, Puzey (2008) has investigated minority-language road signs in Norway, Scotland, and Italy, while (Moriarty, 2014b) has studied Irish-language road signs in Ireland. Similarly, Pietikäinen (2014) has examined the use of Sámi in signs in a Sámi village in northern Finland, while Heller, Pujolar, \& Duchêne (2014) have examined the 
use of local languages in Switzerland and Catalonia from a centre-periphery perspective as related to tourism and exoticization. Coupland (2012) has analysed how Welsh- and English-medium signs in Wales relate to, e.g., double monolingualism, national resistance, and exoticizing tendencies. Our research also fits in with studies of the linguistic landscape situation in other European capitals, such Berlin (Papen, 2015) and Tallinn (Soler-Carbonell, 2015). Beyond Europe, our study has parallels with Johnson (2017), who has studied the linguistic landscape of New Zealand with a view to assessing the ways in which it reflects the current status of te reo Māori.

\subsection{Methodology}

Our study is a qualitative examination of the linguistic aspects of Nuuk signs. Our dataset was collected during a fieldwork trip between 8 and 23 May 2017 in Nuuk and consists of approximately 90 images. The data were chosen by means of a purposeful (selective) sampling method following time spent in the field and consisting of information-rich typical cases (Patton, 2002; Emmel, 2013: 157-167). A quantitative analysis is beyond the scope of this paper. Bias has been avoided by collecting randomized data from a representative selection of different indoor and outdoor spaces (cf. Kallen, 2010) in the main thoroughfares of Nuuk (namely the streets Kuussuaq, Aqqusinersuaq, Imaneq, Samuel Kleinschmidtip Aqqutaa, Jens Kreuzmannip Aqqutaa, Dronning Ingridsvej, Noorlemut, Inspektørbakken, as well as the main roads of its suburbs Nuussuaq (namely the streets Nuussuaq and Sangoriaq) and Qinngorput (namely the streets Hans Lyngep Aqqusernga), the main bus route linking Qinngorput to the city centre (namely the roads Pisisseq and Qarsoq), the University of Greenland, and the Nuuk airport. 
The categories of signs selected for inclusion in our sample are based on Kallen (2010: 43), who divides public spatial domains into the following five zones: 1) the civic frame (space governed by the state), 2) the marketplace (the world of commerce), 3) portals (e.g. airports, banks, internet cafés, TV channels), 4) the wall (graffiti and posters), 5) the detritus zone (rubbish on the ground and in bins), 6) the community (social clubs and leisure), and 7) the school. Our paper excludes 5) the detritus zone, but includes signs representing all the other spaces.

Our analysis of the data is organized into three main categories according to the theory of centre vs. periphery, namely a) signs where West Greenlandic is at the centre, b) signs where Danish is at the centre, and c) signs where English is at the centre. We classify a language as being at the centre when it occupies the sole or most prominent position on a sign (i.e. when the sign is monolingual or when the language in question appears at the top of the sign, at the left, in a larger font, or in a bolded font). We recognize that in some situations the situation is in flux (e.g. the case of road signs, in which policy is shifting incrementally, resulting in a mixed picture at the time of analysis), and acknowledge this complexity where relevant in the analysis.

Within each of these three main categories, we have grouped the signs into subcategories based on content. Hence, within the category of West Greenlandic signs at the centre there are official institution signs; public information sign; supermarket signs; informal community-produced advertisements; road signs; and traditional pub signs. Within the category of Danish signs at the centre there are construction and home improvement signs; public health and safety signs; and a TV station sign. Within the category of English signs at the centre there are international shipping signs; local retail, restaurant, and services signs; and wall murals and graffiti. For each category and 
subcategory of signs we investigate the language choice and placement from the perspective of Blommaert's (2007) notions of indexes within his theory of orders of indexicality, as well as considering the primary audience according to Blommaert's (2007) concepts of scope (local vs. global), and scope (exclusive vs. egalitarian). Our examination also considers whether the choice of language reflects informational value (i.e. the dissemination of practical information to the audience), symbolic value (i.e. to evoke certain connotations, as a tool of commodification, to celebrate cultural identity, or for transgressive purposes), or a combination of the two. Within this framework, we also acknowledge Blommaert's (2007) concept of polycentricity, which highlights the fact that what is central and in the periphery varies depending on the situation; thus, what is central from a Greenlandic perspective may be peripheral from a global one. Furthermore, we take into account Scollon \& Scollon's (2003) discussion of geosemiotics and the notion that signs are mobile resources, meaning that the space in which a given sign is situated adds to its meaning and interpretive force. For example, graffiti is often located in a liminal space and as such may be situated outside mainstream society, i.e. in the periphery, whereas hospital and other state institution signs are manifestations of power and centrality, and are often located in public and prestigious locales. However, within this framework it is nevertheless necessary to acknowledge that signs, locations, and types of establishments can combine in multiple ways to produce multiple effects, and so the relationship between a given sign and its placement is not always clear-cut.

The data under examination includes company names and logos as well as descriptive labels and more complex linguistic material (e.g. warnings, instructions, etc.) With respect to company names, our approach has been to include in our investigation only those names which are themselves words in the language in question (such as the 
supermarket name Pisiffik, which is a Greenlandic word meaning 'shopping place' or the shopping centre name Nuuk Playground, in which Playground is an English lexical item that does not exist independently in Greenlandic or Danish), or have morphological properties exclusive to a particular language (e.g. the supermarket name Brugseni, which is a proper noun with a West Greenlandic nominal suffix $-i$ ) rather than simply proper nouns or numbers that are not lexical items in any of the three languages under discussion. Inclusion of lexical items serving as names adds an important measure of depth to the analysis by allowing us to examine the symbolic role of West Greenlandic, Danish, and English within the Nuuk linguistic landscape (as the choice of a particular language in a shop name carries important indexical value, even if customers do not necessarily need to understand the language in question in order to access the shop).

Our analysis of the signs is supported by complementary semi-structured interviews with seven West Greenlandic-Danish bilingual Nuuk residents, who were asked to comment on their views on and use of the signs under analysis. The interviews consisted of a series of open-ended questions on the functions and perceptions of the West Greenlandic, Danish, and English languages as appearing on monolingual, bilingual, and trilingual signs in Nuuk public places. The interviews were conducted between 1 and 8 August 2019. There were five female and two male participants aged between 20 and 40 (anonymized here as F1-F5 and M1-M2), and each interview lasted between 19 and 35 minutes. The participants' anonymized responses are included where relevant in the discussion of the different categories of signs. Likewise, we consulted with Oqaasileriffik, the Language Secretariat of Greenland, who referred us to relevant legislation and articles. 
Our research focus is on the function and position of the different languages on the signs in various sociolinguistic contexts, rather than on the details of their content per se. As such, we have translated the relevant elements of the signs under examination, but have not included linguistic analysis or complete translations of some of the longer signs as this would not be feasible and is not pertinent to the research. With respect to broader questions regarding language use in Nuuk, there is at present a lack of published research on the general sociolinguistic situation in Greenland, and as a result we are unable to link our discussion of the linguistic landscape to scholarly work on bilingualism, language preferences, literacy, and other relevant issues. Likewise, primary research on language use in the various contexts in which the signs appear (i.e. schools, supermarkets, etc.) is beyond the scope of the present analysis. As an initial investigation into the sociolinguistic situation in Nuuk, our research is thus primarily descriptive in nature and does not lend itself to quantitative analysis or the drawing of far-reaching theoretical conclusions. These topics remain desiderata for future research.

\section{Analysis}

\subsection{West Greenlandic at the centre}

West Greenlandic is clearly at the centre in signs appearing in a number of different contexts in Nuuk. These contexts include state institutions, discussed in 3.1.1, public information signs, discussed in 3.1.2, supermarket signs and localized product labels, discussed in 3.1.3, road signs, discussed in 3.1.4, informal community-produced advertisements and announcements, discussed in 3.1.5, and pub signs, discussed in 3.1.6. 


\subsubsection{Signs marking state institutions}

West Greenlandic is at the centre of signs marking state institutions in Nuuk. Such signs are invariably bilingual, with West Greenlandic on top and Danish underneath. This pattern is visible in Figures 1-2 below. In some official signs, the West Greenlandic text, in addition to appearing above the Danish, is placed in bold, whereas its Danish equivalent is in regular font. This can be seen in Figure 2. This serves to draw additional attention to the West Greenlandic in comparison to the Danish, thereby further raising the prominence of the former and highlighting its status as the primary language.

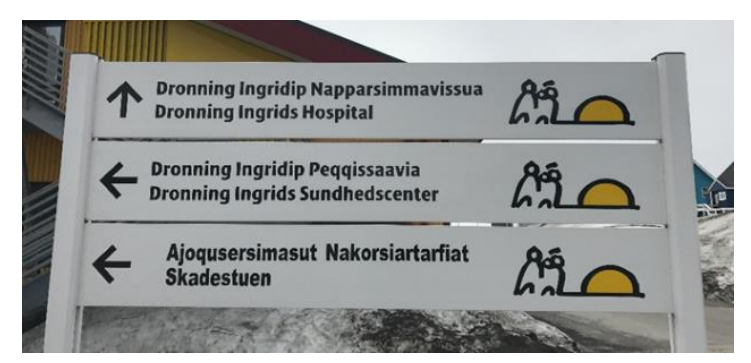

Figure 1. Bilingual hospital sign

'Queen Ingrid's Hospital' (West Greenlandic followed by Danish)

'Queen Ingrid's Health Centre' (West Greenlandic followed by Danish)

‘Accident and Emergency Room' (West Greenlandic followed by Danish)

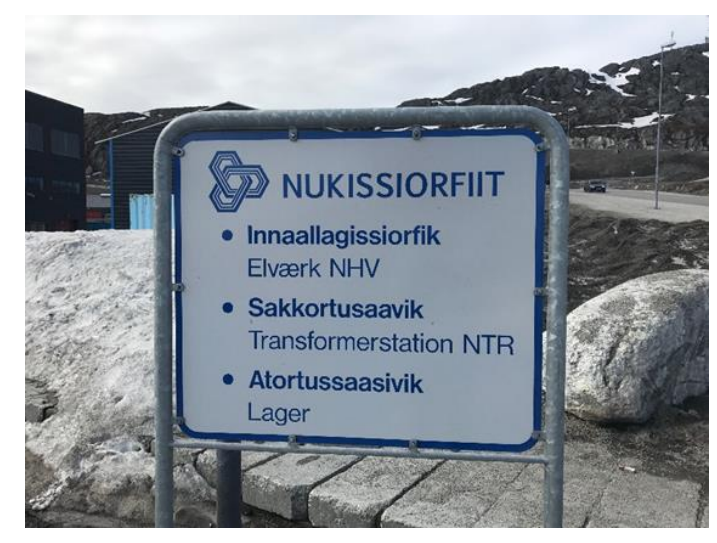

Figure 2. Bilingual state-owned energy company sign 
‘Greenland's Power Supply' (title in West Greenlandic only) ${ }^{1}$

'Power Plant' (West Greenlandic followed by Danish)

‘Transformer Station' (West Greenlandic followed by Danish)

'Warehouse' (West Greenlandic followed by Danish)

The official government policy of placing Greenlandic at the centre is also visible in educational environments. In fact, in these settings West Greenlandic may be the only language employed, to the exclusion of Danish. This can be seen in Figures 3 and 4. In Figure 3, a kindergarten is designated solely by the name Umiaq, a West Greenlandic noun for an open sea boat (as illustrated in the accompanying drawing). Similarly, in Figure 4, Atuarfik Hans Lynge 'Hans Lynge School', a comprehensive school in the Nuuk suburb of Qinngorput, is labelled only by the West Greenlandic word for 'school' and the proper name Hans Lynge. Hans Lynge was a prominent Greenlandic artist and playwright; although his name looks Danish, he is an important national figure. The use of West Greenlandic in these cases has a symbolic value as well as an informational one, reflecting the fact that instruction at these levels is in West Greenlandic only.

\footnotetext{
${ }^{1}$ The name Nukissiorfiit is a proper noun translatable as 'Greenland's Power Supply'; it is actually the plural form of the West Greenlandic common noun nukissiorfik, which means 'power plant'. See section 3.1.3 for discussion of monolingual West Greenlandic company names.
} 


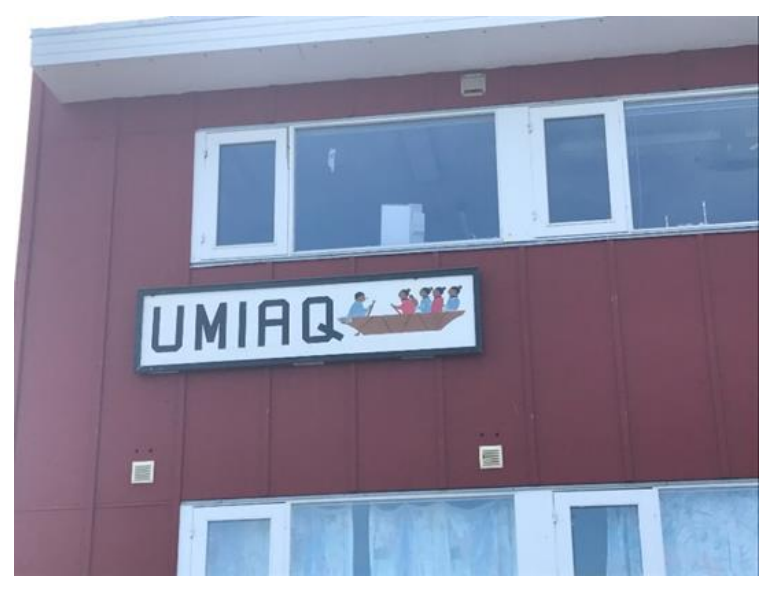

Figure 3. Kindergarten Umiaq

'Open sea boat' (West Greenlandic only)

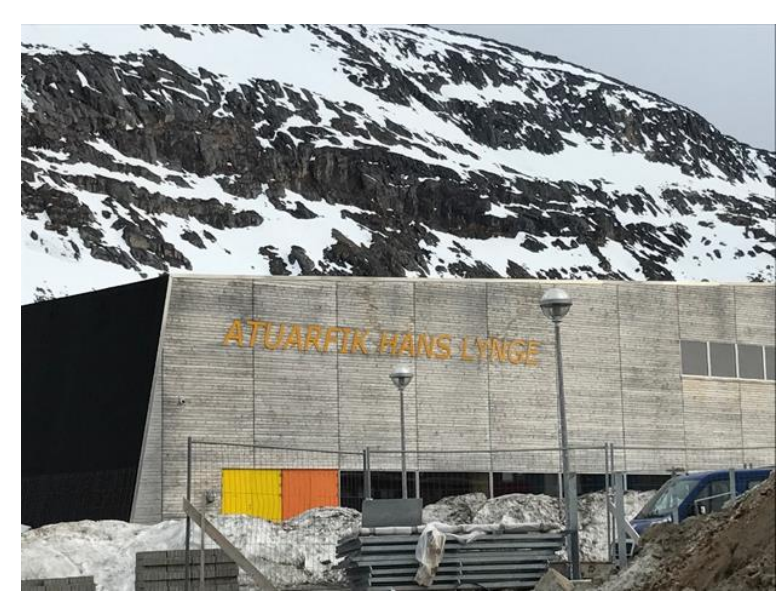

Figure 4. Hans Lynge [comprehensive] school

‘Hans Lynge School’ (West Greenlandic only)

In the official signs seen in the tertiary setting, the linguistic policy is slightly different. West Greenlandic is still firmly in the centre, but a trilingual policy (West Greenlandic followed by Danish and then English) is strictly enforced. This trilingual policy is consistently seen throughout the university's signage. This reflects the university's role as an international institution: though primarily geared towards the local West Greenlandic-speaking population, it is also equipped to accommodate Danish-speaking 
students as well as international ones. This is illustrated in Figure 5, a trilingual sign at the University of Greenland. Here, the prominence of West Greenlandic can be seen not only in its position, but also in the fact that a bigger font has been selected for it than for Danish and English.

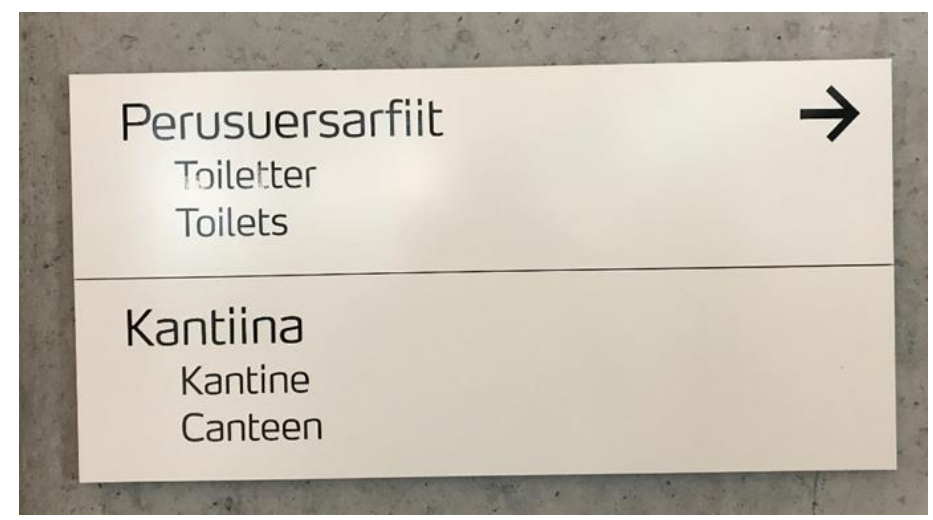

Figure 5. A trilingual sign at the University of Greenland

‘Toilets' (West Greenlandic followed by Danish and English)

'Canteeen' (West Greenlandic followed by Danish and English)

This placement of West Greenlandic at the centre of state institution signs is expected given the fact that West Greenlandic has been the only official language of Greenland since 2009. Thus, the prioritization of West Greenlandic in prominent loci of state power is a clear indication of the way in which West Greenlandic has been brought to the centre and its status has been raised in the public sphere since 2009. This echoes practices in Wales, where state-produced signs are bilingual with Welsh first (Coupland, 2012). In some respects the Welsh case resembles that of Greenland in that both are devolved or semi-autonomous entities with a minority language that has official status. However, Greenland differs from Wales in that, whereas in Wales the bilingual policy reflects the fact that English also has official status, in Greenland Danish lacks such status. Thus, the 
fact that all of these Greenlandic signs marking state institutions are bilingual reflects the continuing practical importance of Danish in Greenland, despite the fact that it is no longer an official language of the country. Our interview participants regard the continuing importance of Danish in Greenland as stemming from practical, political, and cultural-historical factors. M1 stated that Danish is a necessary component of sings in Greenland because 'Greenland belongs to Denmark', while F2 observed, 'I also think that it's because we in Greenland are very traditional and we have had Danish and Greenlandic side by side for many, many years'. These top-down bilingual signs with West Greenlandic at the centre have a primarily local audience, and have a twofold function. While they are clearly informational, as they convey institutional names and other practical details, they are also strongly symbolic.

\subsubsection{Public information signs}

Public information signs (which may be produced by the state or by private companies) are another subcategory where West Greenlandic is clearly at the centre. As in the case of signs marking state institutions, public information signs are typically bilingual with West Greenlandic on top and Danish on the bottom. This can be seen in Figures 6 and 7.

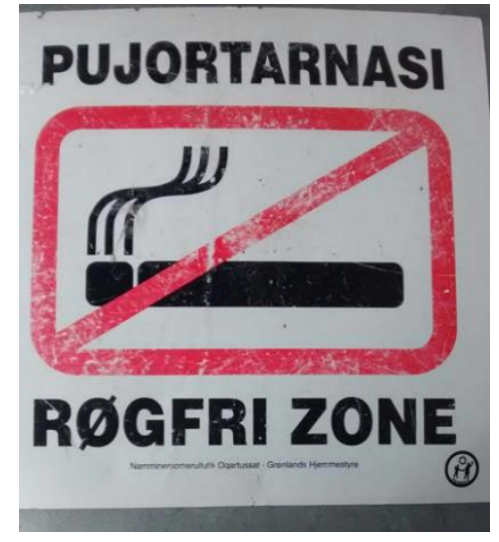


Figure 6. Bilingual no smoking sign

'Do not smoke' (West Greenlandic)

'Smoke-free zone' (Danish)

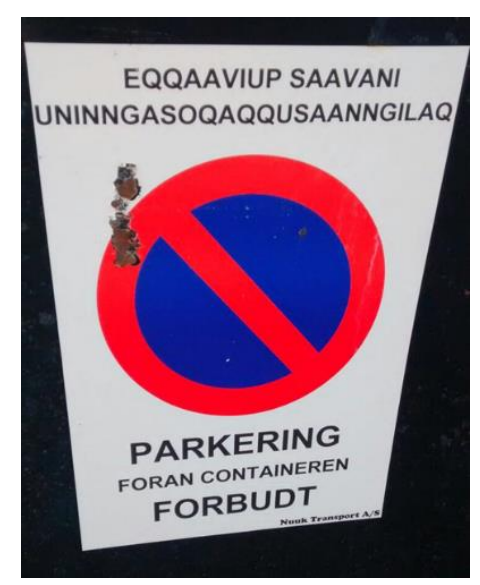

Figure 7. Bilingual sign on a waste container

'No parking in front of the container' (West Greenlandic)

'Parking in front of the container is forbidden' (Danish)

Public information signs closely resemble signs marking state institutions in that they typically place West Greenlandic at the centre and are bilingual with Danish. As above, the central position of West Greenlandic has a primarily informational function, but it is important to note that even so, it has a symbolic one as well. This is evidenced by the fact that our interview participants, all of whom are native speakers of West Greenlandic and use the language in their everyday lives, stated a preference for reading public information signs in Danish: as F2 said, 'I mostly focus on the Danish'. The reasons for participants' preference for Danish are practical: F4 stated that she reads the Danish 'because it's shorter', while F1 said that 'it's easier to understand, read in Danish. It's quicker. It's easier to find times, locations.' M2 elaborated on these points, saying that 'I read Danish 
first. In Greenlandic it's a whole page, in Danish it's half or less. It's a lot easier to read in Danish than it is to read in Greenlandic for me even though I have a Greenlandic mother and father.' This indicates that even though West Greenlandic is in the central position, the presence of Danish can actually be of more practical use for West Greenlandicspeaking locals.

\subsubsection{Supermarket signs and product labels}

West Greenlandic is also largely in the centre in the case of supermarket signs. Most signs within supermarkets, i.e. labels indicating different sections (meat, vegetables, wine, etc.), information about special offers, and other customer notices, are bilingual with West Greenlandic on top and Danish below. An example of this is the customer satisfaction sign shown in Figure 8 below; see also Figure 10 for a bilingual opening hours sign outside a supermarket. 


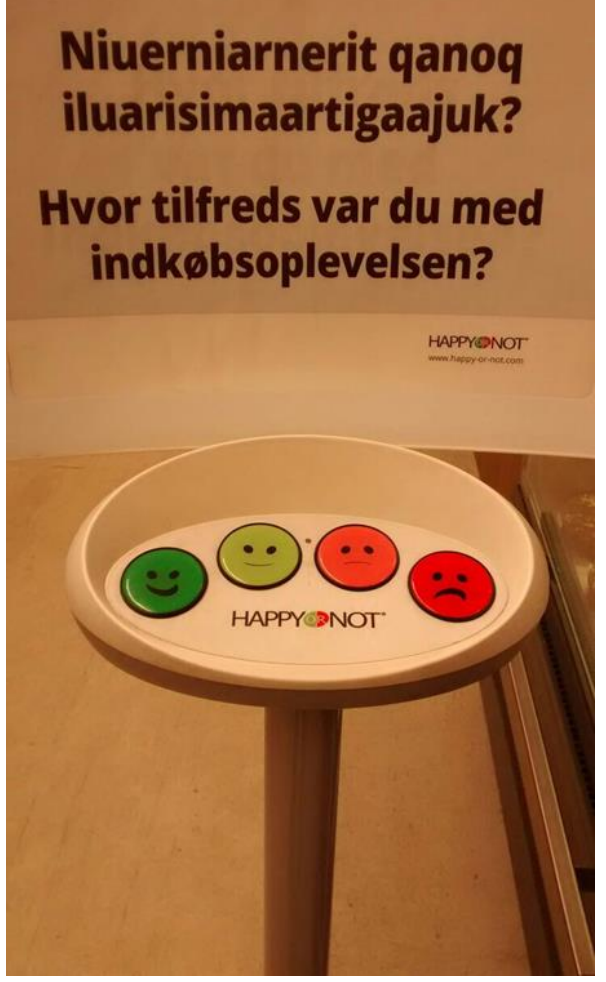

Figure 8. Bilingual supermarket customer satisfaction sign

'How happy were you with your shopping experience?' (West Greenlandic followed by Danish)

Another way in which West Greenlandic has been brought to the centre in supermarket contexts is by renaming Danish brands and shop names for the local Greenlandic consumer. For example, the Danish supermarket chain Brugsen is called Brugseni in Greenland; the addition of the final $-i$ is the standard way of adapting loanwords into West Greenlandic (cf. cykeli 'bicycle', from Danish cykel). A further domesticating adaptation can be seen in Figure 9, which shows the sign for a mini branch of Brugseni in central Nuuk. In order to signpost that this is a smaller version of the supermarket, the name appears as Brugseneeraq, with the $-i$ replaced by the West Greenlandic diminutive suffix 
-eeraq and a translation value of 'little Brugsen'. In this case, West Greenlandic is clearly dominant, as there is no Danish equivalent given for the supermarket's name. In this case the Greenlandic localization is heightened by the addition of a red and white sun design, based on the Greenlandic flag, inside the $g$ of the name (see Valijärvi \& Kahn, 2018 for discussion of the visual symbols and images in Nuuk signs).

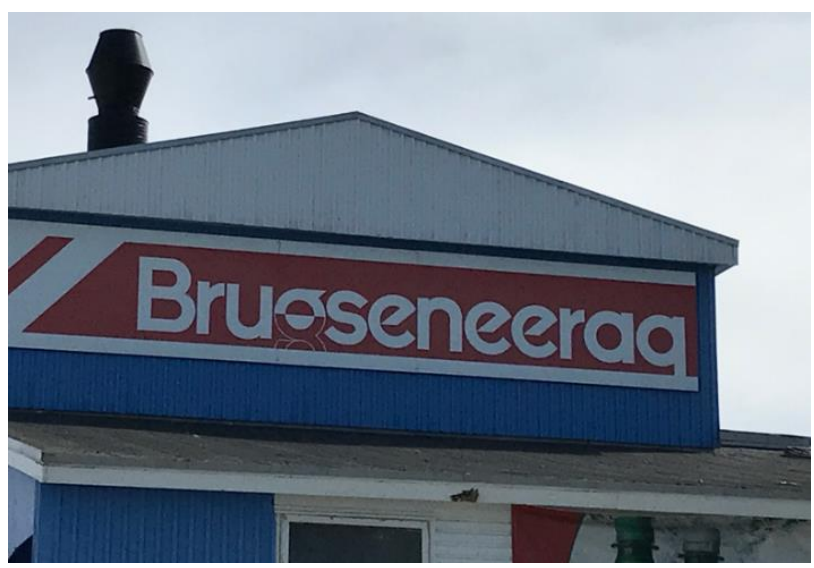

Figure 9. Supermarket sign

'Little Brugsen' (West Greenlandic only)

Another example of monolingual localization can be seen in Figure 10, a sign for the popular supermarket chain Pisiffik. While the opening hours information on the sign is bilingual, the name of the shop is West Greenlandic only (pisiffik literally means 'shopping place' in West Greenlandic). Like the case of Brugseni, this is a clear case of localization because Pisiffik is part of a Danish-Norwegian-Greenlandic supermarket conglomerate, and the Danish and Norwegian branches of the supermarkets have their own localized names, e.g. Joker, Kiwi, and Meny in Norway, and Bilka, Føtex, and Netto in Denmark. 


\section{ULLUT TAMAASA HVER DAG \\ $07.00-22.00$ PISIFFIK}

Figure 10. Bilingual supermarket sign

'Every day' (West Greenlandic followed by Danish)

'Pisiffik' (shop name; West Greenlandic only)

With respect to the languages on supermarket packaging, most foodstuffs for sale in Greenland are imported from Denmark and the labels do not undergo localization. Thus, in some cases the labels are monolingual in Danish, but more frequently they are multilingual with versions in the state languages of the bigger Nordic countries, i.e. Norwegian, Swedish, and Finnish. West Greenlandic is not included. This is due to the small size of the Greenlandic market in comparison to the Danish, or pan-Nordic, one: it is not financially or practically viable for special West Greenlandic-language labelling to be produced for this small pool of consumers, who can almost invariably read Danish. As such, in this regard economic and practical concerns outweigh ideological ones rooted in the state policy of bringing West Greenlandic to the centre. (Note that food packaging and other imported items are exempt from the 2012 amendment to the language law in Greenland mandating the inclusion of West Greenlandic on signs; see Sermitsiaq, 2012). As F2 observed in this respect, 'officially we have one language, Greenlandic. It's the most important one. And officially everything should be in Greenlandic. But we cannot 
force Denmark or the rest of Europe to translate everything into Greenlandic. [...] And we wouldn't be able to buy it, as it would get more and more expensive.'

The only exceptions to this pervasive tendency are a small number of products that are particularly central to the Greenlandic context and have been produced specifically for a local market: ship biscuits (Figure 11), powdered milk, cordial or juice concentrate (Figure 12), and coffee (Figure 13). In these few cases only, the product packaging follows the dominant model observed above: the writing is bilingual in West Greenlandic and Danish, with the West Greenlandic first (in the case of the coffee, the Danish version is on the reverse side of the package). The coffee package contains a subheading explaining that this product is particularly designed to be suited to Greenlandic water (which is of a different hardness level than e.g. Danish water).

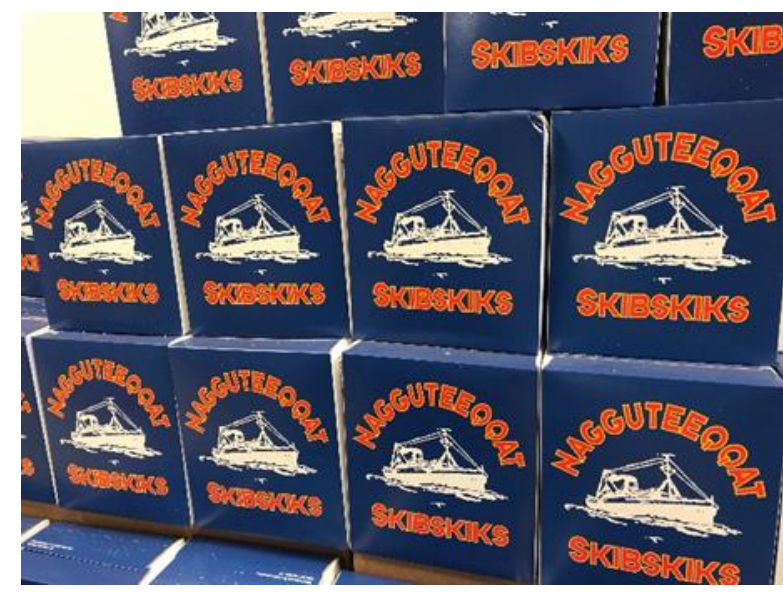

Figure 11. Bilingual ship biscuits label

'Ship biscuits' (West Greenlandic and Danish) 


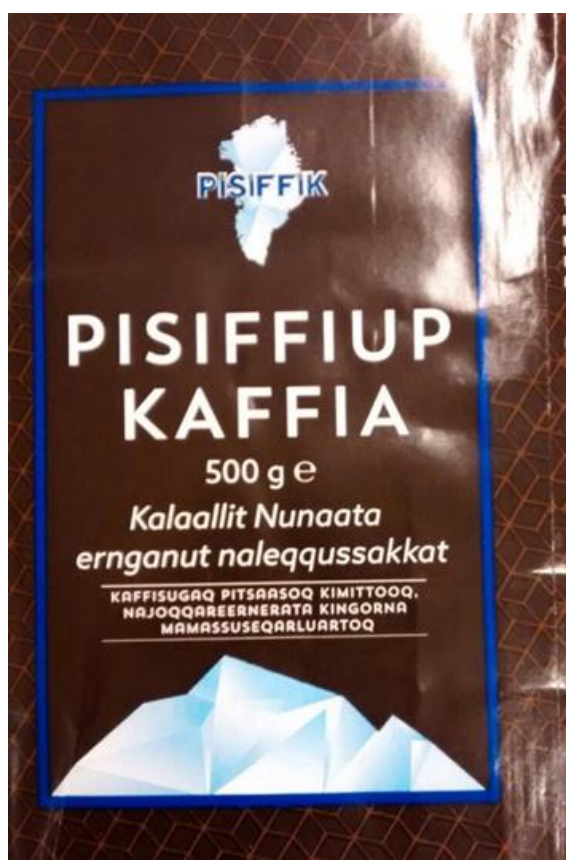

Figure 12. Pisiffik supermarket's own coffee brand label

'Pisiffik's coffee, specially suited to Greenlandic water' (West Greenlandic; Danish version on the back of the package)

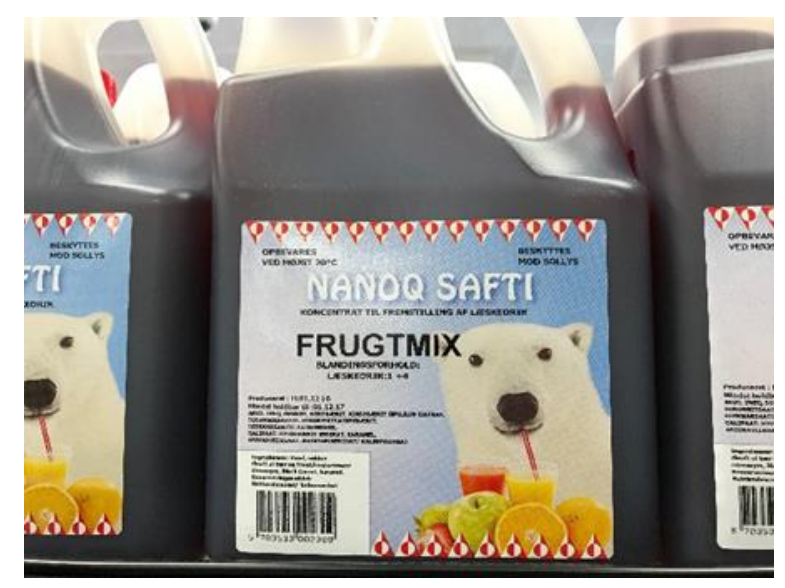

Figure 13. Juice concentrate

'polar bear juice' (West Greenlandic)

'fruit mix' (Danish)

Bilingual West Greenlandic-Danish signs with West Greenlandic at the centre in supermarket contexts have a primarily local audience. In these settings, West Greenlandic 
has an informational value (i.e. relaying information about the whereabouts of supermarket items, special offers, etc.), but also a symbolic one in many cases. With respect to the West Greenlandic juice, coffee, and biscuit packaging, F5 commented that 'you want to highlight the fact that it's Greenlandic, the language that we should speak.' The symbolic function is extremely prominent in the case of supermarket names, where West Greenlandic words used as titles (Pisiffik) or Danish names that have undergone linguistic localization (Brugseni and Brugseneeraq) are not needed for conveying information, but rather serve to link the shops to the local Greenlandic environment. In these cases, interview participants expressed skepticism about the symbolic localization. With respect to Brugseni, F5 and M2 were of the opinion that the expense involved in renaming the shop was a waste and that the funds could have been invested in projects bringing a greater benefit to the Greenlandic people. Similarly, with respect to Pisiffik, F2 stated that 'their focus is to be Greenlandic, maybe to hide the fact that they are foreign. [...] They want to sound Greenlandic but they are not Greenlandic.' More subtly, the informational supermarket signs (e.g. opening hours and customer satisfaction surveys) also have symbolic value, because, as in the case of other bilingual signs discussed above, West Greenlandic speakers such as our participants display a preference for reading the Danish versions because they feel that it is easier to process information quickly in that language. This symbolic use of West Greenlandic can be compared to the symbolic use of Māori in the signs at the shopping centre The Base north of Hamilton in New Zealand (Johnson 2017). 


\subsubsection{Informal community-produced advertisements}

West Greenlandic is also commonly at the centre in signs for leisure events and social clubs. These types of signs are typically bilingual, with West Greenlandic appearing first and Danish underneath it. This pattern is evident in the poster advertising a concert in Figure 14. Similarly, while the flea market poster in Figure 15 has the name of the event in Danish, the details following it are in West Greenlandic and Danish.

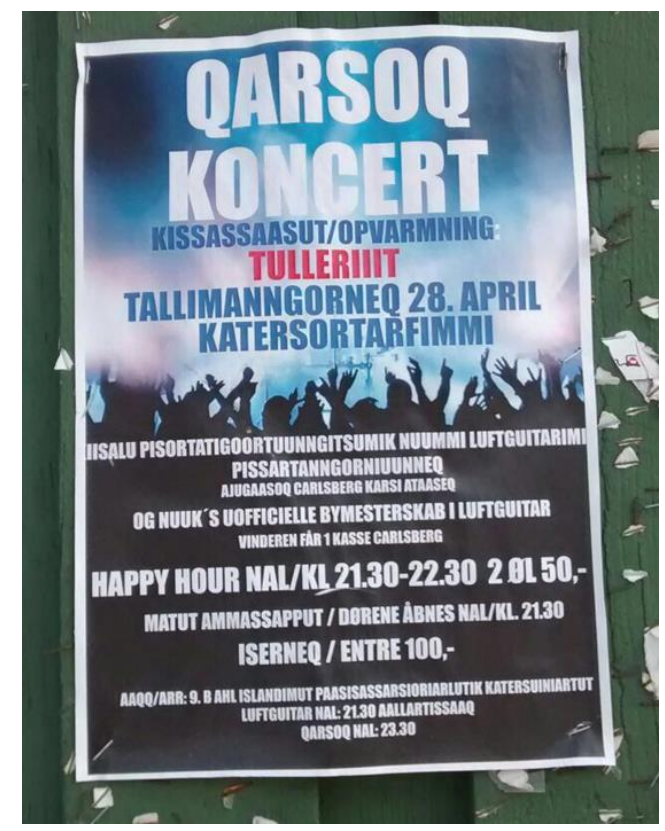

Figure 14. A bilingual poster at a bus stop in central Nuuk advertising a concert

'Qarsoq [band name] concert; warm-up Tulleriit [band name]' (West Greenlandic followed by Danish)

'Friday 28 April in the community centre' (West Greenlandic only)

'And Nuuk's unofficial city champions in air guitar; the winner gets a crate of Carlsberg' (West Greenlandic followed by Danish) 


\section{Loppemarked}

Atuarfik ASK-mi atuartut 5.b paasisassarsiorlutik angalanissaanut katersuiniarlutik atuarfimmi ASK-mi Aula-mi sukujunnik tuniniaaniarput.

Arfininngorneq 6/5-2017 nal. $11.00-15.00$

$5 . b$ i ASK indsamler penge til studierejse, derfor afholder loppemarked i skolen

ASK pá Aulaen pà lørdan den $6 / 5-2017 \mathrm{kl} .11 .00-15.00$

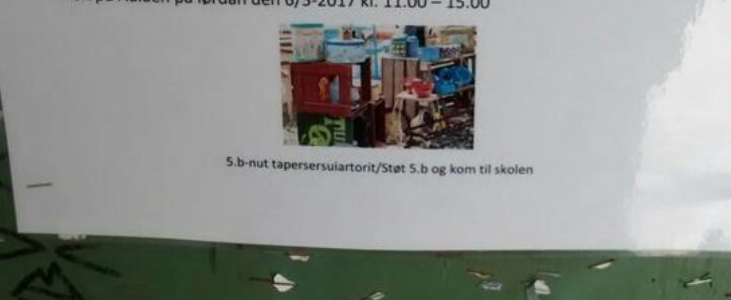

Figure 15. A bilingual poster at a bus stop in central Nuuk advertising a flea market

'Flea Market' (Danish only)

'Class $5 \mathrm{~b}$ in the ASK school is collecting money for a class trip; therefore a flea market will be held in the ASK school in the school hall on Saturday 6/5/2017 11-15:00' (West Greenlandic followed by Danish'

The signs in this subcategory have a primarily local bilingual audience. The placement of West Greenlandic in the centre is largely informational, but follows the pattern seen elsewhere in the civic and commercial landscape of Nuuk whereby the bilingual model with West Greenlandic on top also has a symbolic function to some degree, since West Greenlandic speakers can also generally read Danish fluently and sometimes prefer to the Danish version.

\subsubsection{Road signs}

Road signs are another subcategory where West Greenlandic is often at the centre, but the centrality manifests itself very differently from the general trend towards bilingual signage discussed above. Nuuk road signs are always monolingual, and may be in either 
West Greenlandic or Danish. The distribution of the languages is not based on geography; thus, For example, the Danish roads Dronning Ingridsvej 'Queen Ingrid's road' and Inspektørbakken 'inspector hill' in central Nuuk are near the West Greenlandic-language roads Samue Kleinschmidtip Aqqutaa 'Samuel Kleinschmidt's road' and Aqqusinersuaq 'big road'. Rather, the distribution of languages is based on the period in which the roads were named, with older roads tending to have Danish-language signs while newer ones are more commonly in West Greenlandic. When asked what interview participants thought about the monolingual road signs, they expressed a preference for this system, saying that they would not want to have bilingual West Greenlandic-Danish road signs because it would be too much information to process on a small sign and it is better to have one language only, whether West Greenlandic or Danish. (Cf. Puzey 2008 on the case of Norway, Scotland, and Italy, where attempts to institute road signs in the local minority languages have all met with degrees of opposition on practical and/or ideological grounds.) The strictly monolingual road sign policy in Nuuk can be contrasted with the linguistic conventions governing road signs in many other bilingual and multilingual countries, where the selection of languages is often much more systematic; for example, in Wales, road signs are strictly bilingual with Welsh on top and English on bottom (Welsh Government 2018); in Israel, road signs are often trilingual in Hebrew, Arabic, and English (BBC, 2009; see also Ben-Rafael, Shohamy, Amara, \& Trumper-Hecht, 2006 for discussion of trilingualism in top-down signs in Israel, including road signs, as shown on image 1 on p. 28, and Bigon \& Dahamshe, 2014 for analysis of bi- and trilingual road signs in the Galilee). Road signs are thus an unusual case of West Greenlandic gradually moving from the periphery to the centre. In this respect, the policy to shift over time to a West Greenlandic monolingual road sign policy is aimed primarily at a local audience, 
who can read Greenlandic, and is informational as well as symbolic (since West Greenlandic speakers are also comfortable reading Danish road signs).

\subsubsection{Traditional pub signs}

Like road signs, traditional, long-established pubs and restaurants frequented by a West Greenlandic-speaking clientele often have monolingual West Greenlandic names, e.g. Maximut 'Max's Place' in central Nuuk, as shown in Figure 16. This model resembles that of supermarkets with monolingual West Greenlandic names (see 3.1.3).

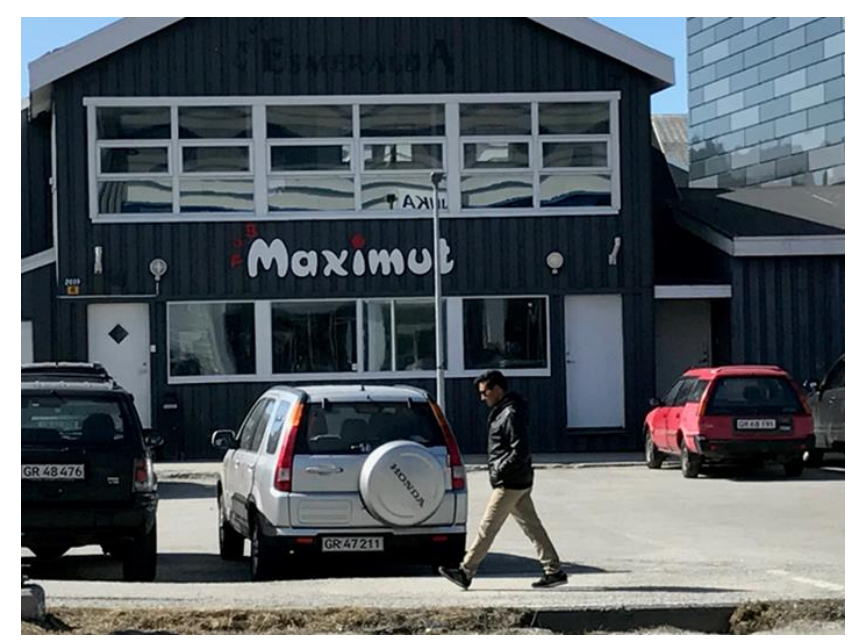

Figure 16. Pub Maximut in the centre of Nuuk

'Max’s Place' (West Greenlandic)

The effect of placing West Greenlandic at the centre here is somewhat different from that of the case of Brugseni and Pisiffik, as our interview participants reported that pubs and restaurants of this type commonly have West Greenlandic names (usually a personal name followed by the West Greenlandic allative suffix -mut, meaning 'X's place') because they are for a local clientele and have an 'old-fashioned, homely Greenlandic 
atmosphere' which the monolingual West Greenlandic name reflects and evokes. Thus, as in the case of the supermarkets, the name has primarily symbolic value, though it has the effect of evoking different associations.

\subsection{Danish at the centre}

Danish, the former colonial language of Greenland, is at the centre less than West Greenlandic (despite being widely visible in bilingual signs with West Greenlandic occupying a more prominent position, as discussed in the previous section). However, there are certain contexts where Danish is clearly at the centre, meaning either that it is the only language on a given sign, or that it features in a more prominent position than West Greenlandic and/or English. There are three main categories of signs which have Danish at the centre, namely signs for construction and home improvement companies, discussed in 3.2.1, public health and safety signs, discussed in 3.2.2, and TV station signs, discussed in 3.2.3.

\subsubsection{Construction and home improvement signs}

Nuuk signs indicating plumbing, electricity, and repair services are almost exclusively in Danish, with very little West Greenlandic in evidence. This can be seen in Figures 17-19. In Figure 17, the sign for a building business contains the West Greenlandic word sanasut 'builders' but all the services are listed in Danish only. Likewise, the advertisement for a furnishing store (which is related to the construction trade) shown in Figure 18 is printed solely in Danish. Figure 19, which shows a label for the Nuuk transport service, is a particularly noteworthy example of this trend: in addition to being monolingual in Danish, 
it also uses the old Danish name for Nuuk, Godthåb, which is no longer typically in active use in Greenland even in Danish-language contexts.

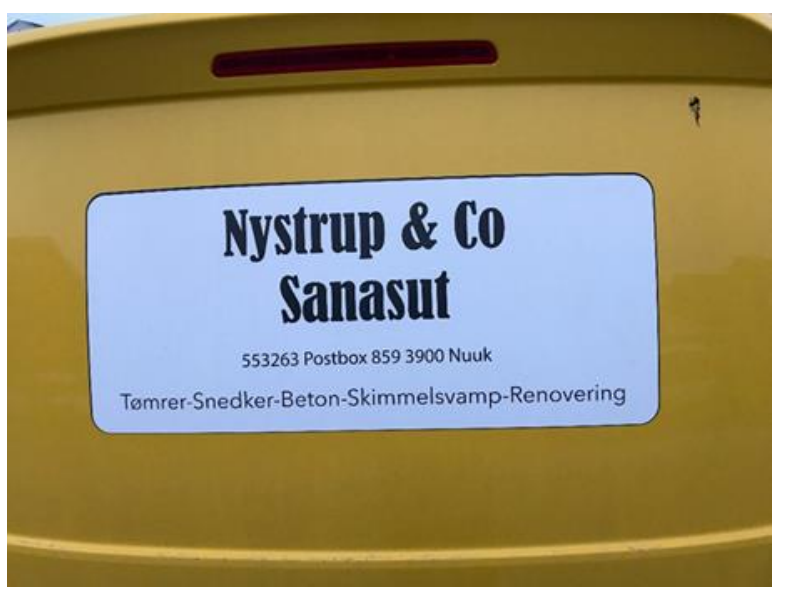

Figure 17. Builder's advert

'Nystrup \& Co Builders' (West Greenlandic)

‘Carpenter, Joiner, Concrete, Mould, Renovations’ (Danish)

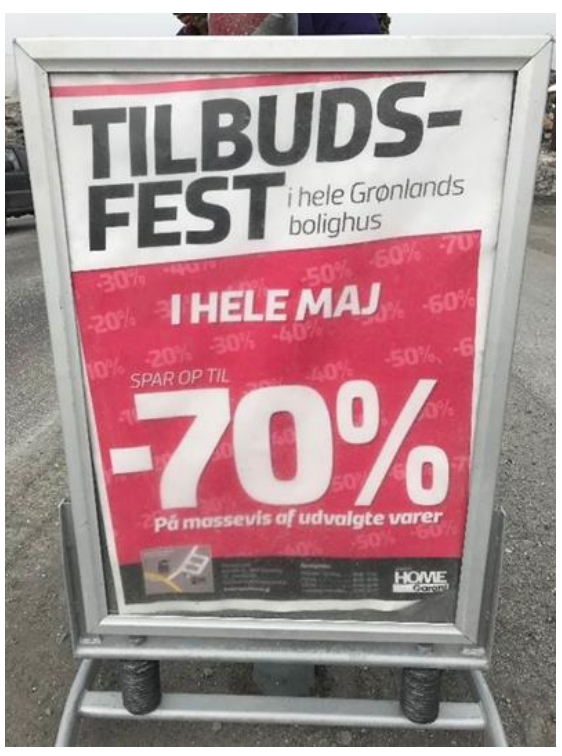

Figure 18. Monolingual sign on road

'Special offers in the entire Greenland Furnishings Store for the whole of May' (Danish) 


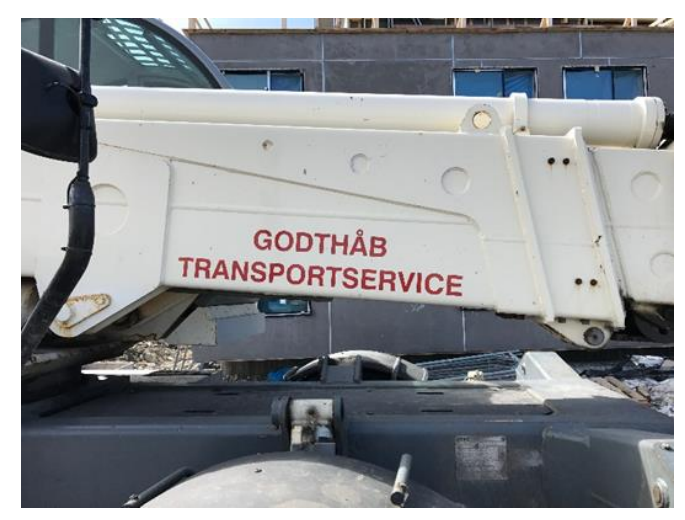

Figure 19. Nuuk transport service

‘Godthåb Transport Service’ (Danish only)

The dominance of Danish in the construction and home improvement sector is largely due to the fact that construction professionals working in Greenland often come from Denmark and do not speak West Greenlandic. Our interview data support this, with participants saying that most tradespeople speak only Danish and the signs reflect this. The use of Danish in this type of setting is informational and practical rather than symbolic. The signs are designed for an audience of Danish-speaking tradespeople (in addition to West-Greenlandic-speaking audiences, who are typically comfortable reading Danish as well). As F1 observed, Danish needs to be used in these types of contexts 'because also those who speak only Danish live here. It is also important.' The lack of West Greenlandic on these signs can be explained by the fact that private companies can apply for an exemption from the 2012 amendment to the language law in Greenland whereby adverts and signs of private companies must be written in West Greenlandic, with Danish, English, and other foreign languages available as supplementary languages (Sermitsiaq 2012). 


\subsubsection{Public health and safety signs}

In many cases, Danish is at the centre in signs issuing warnings and noting public hazards in the case of many signs indicating public danger. This is exemplified in Figure 20, a sign warning the public not to travel on the ice. While the sign is bilingual, the Danish precedes the West Greenlandic. The situation is even more striking in the case of some signs involving an extremely dangerous situation, in which the West Greenlandic is omitted entirely and the sign is monolingual in Danish, as in Figure 21. A similar case is shown in Figure 22, an emergency exit sign at Nuuk airport in which West Greenlandic appears on top and in larger font, whereas Danish appears in smaller letters. This sign conforms to the typical of public information signs as discussed in 3.1.2, in which West Greenlandic is at the centre. However, the official sign has been overridden by the addition of a printed sign saying 'Use main exit' in Danish in large font, with no West Greenlandic.

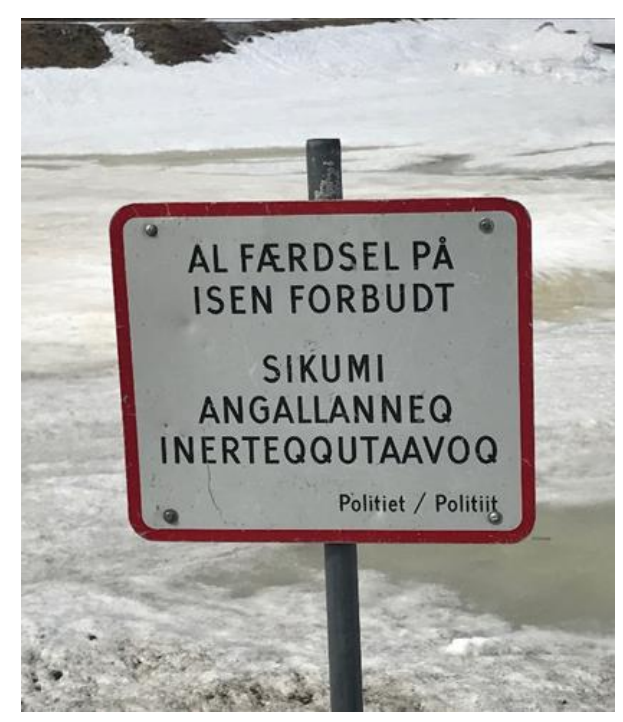

Figure 20. Bilingual police traffic sign

'All traffic on the ice is forbidden' (Danish)

'It is forbidden to go on the ice' (West Greenlandic) 
'The Police' (Danish followed by West Greenlandic)

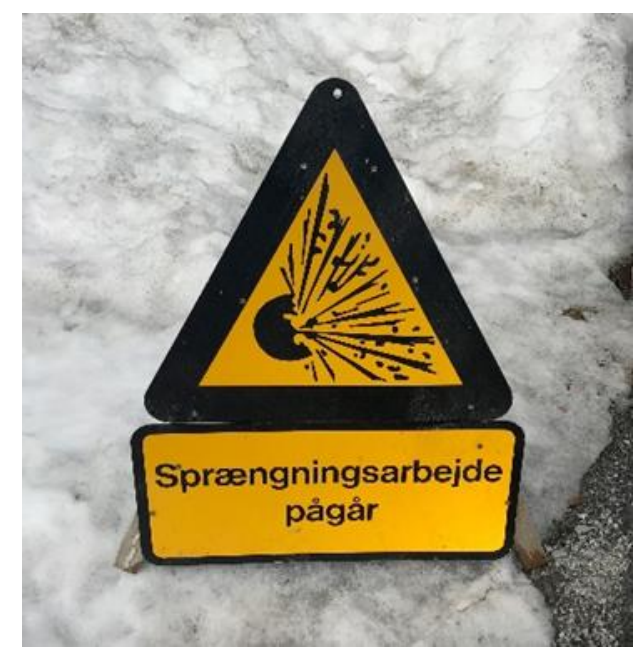

Figure 21. Monolingual building works sign

'Blasting work in progress' (Danish)

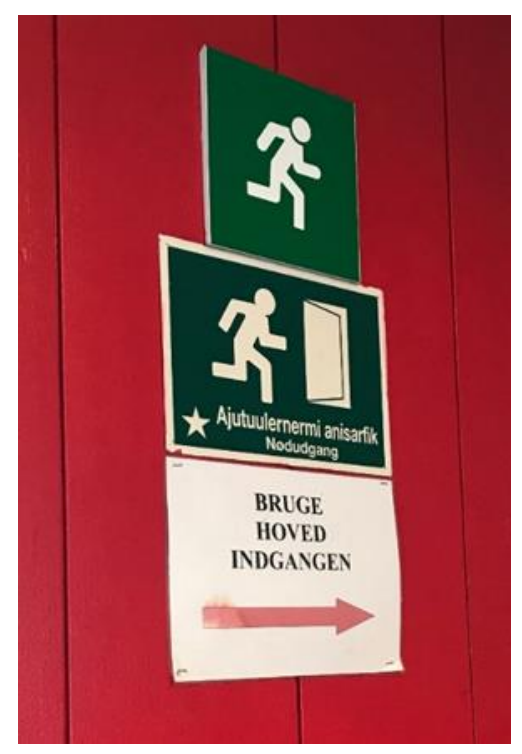

Figure 22. Emergency exit sign at Nuuk airport

'Emergency exit' (West Greenlandic followed by Danish)

'Use main exit' (handmade, Danish only) 
In these cases, the role of Danish as the most prominent or only language has an informational rather than symbolic function. The signs are designed for primarily for local as well as Danish audiences, and the selection of Danish has the effect of making the warnings easily accessible both to Danish speakers without knowledge of West Greenlandic, as well as to West Greenlandic speakers, as the latter can also usually read Danish. This is compounded by the fact that in some cases, the signs have been imported from Denmark and have not undergone localization for practical economic concerns, as in the case of food packaging labels discussed in 3.1.3.Our interview participants commented that the use of Danish as the only, or most prominent, language in warning signs has the effect of making them take the information more seriously: as F2 noted, 'When it is in another language then it must be more serious as more people are meant to understand it. If it is only in Greenlandic then it is only the local ones and we're a bit rebellious.' She goes on to comment that if it is in Danish then she really understands how dangerous it is, and that 'it has more meaning when it is in Danish.' F1 added with respect to the warning signs that 'If it only was in Greenlandic you understand the words but $[\ldots]$ there is more feeling in Danish than in Greenlandic.' Thus, the placement of Danish at the centre in these public health and safety contexts has an important symbolic function for West Greenlandic speakers as well as a practical one.

Danish has also been brought to the centre in an unofficially produced sign about scent policy posted at the University of Greenland, shown in Figure 23. While the trilingual policy visible throughout the university is still in evidence (as discussed in 3.1.1), Danish is at the centre here because the issue is one of public health and safety. While the sign is trilingual and the order of the languages is the same as in the official signs, the title only has Danish and English and the subheading is in Danish only; 
moreover, the Danish portion of the trilingual sign is in bold. This shows that, as in the case of the warning signs discussed above, in cases when matters of public health and safety are at stake, Danish tends to replace West Greenlandic so that quick urgent messages may be relayed efficiently (as it is assumed that readers of West Greenlandic will also understand the Danish).

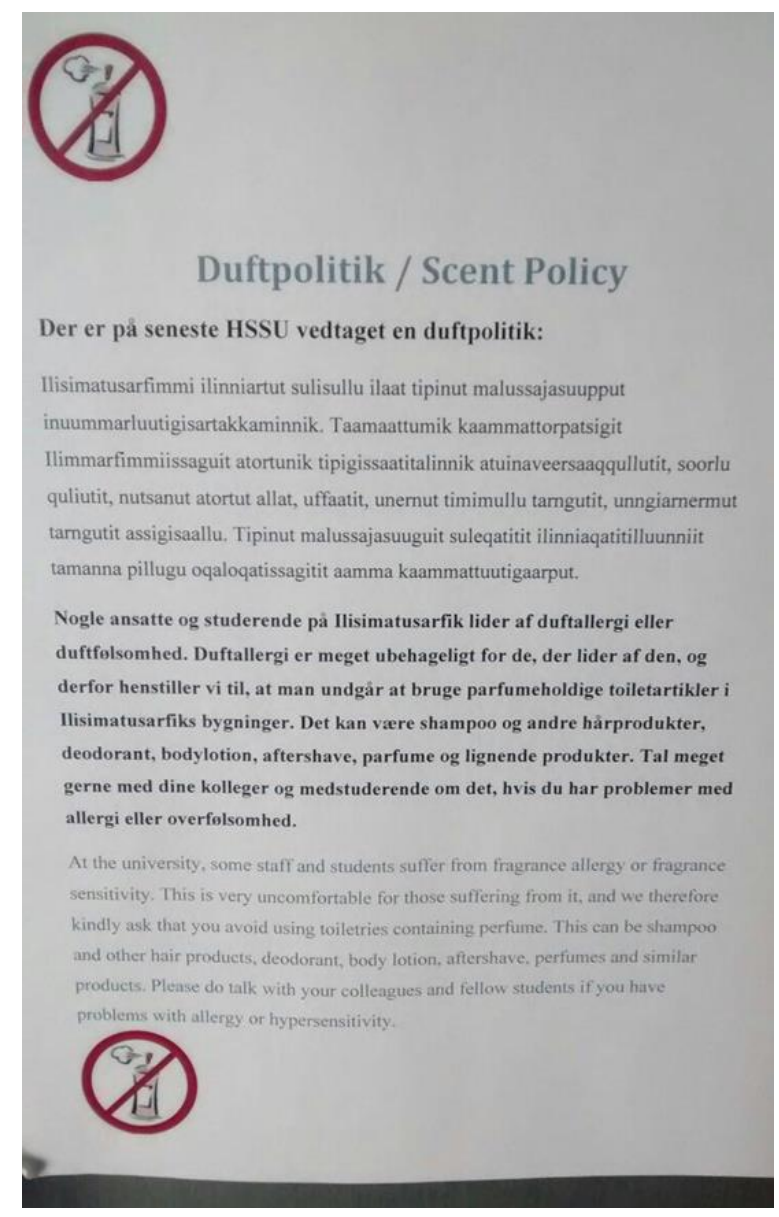

Figure 23. A trilingual scent policy sign at the University of Greenland

'Scent Policy' (title in Danish and English; policy contents in West Greenlandic followed by Danish [in bold] and English) 


\subsubsection{TV station sign}

Although Greenlandic media (i.e. print and online newspapers and radio) are typically bilingual in West Greenlandic and Danish, the signage for the television company Nuuk TV (renamed Nanoq TV as of May 2017), a subsidiary of the media company Nanoq Media, is monolingual in Danish (Figure 24), even though the name of the company includes the West Greenlandic word nanoq 'polar bear'). This monolingual sign reflects fact that the broadcasting content of the company is almost exclusively in Danish (Nanoq Media 2020).

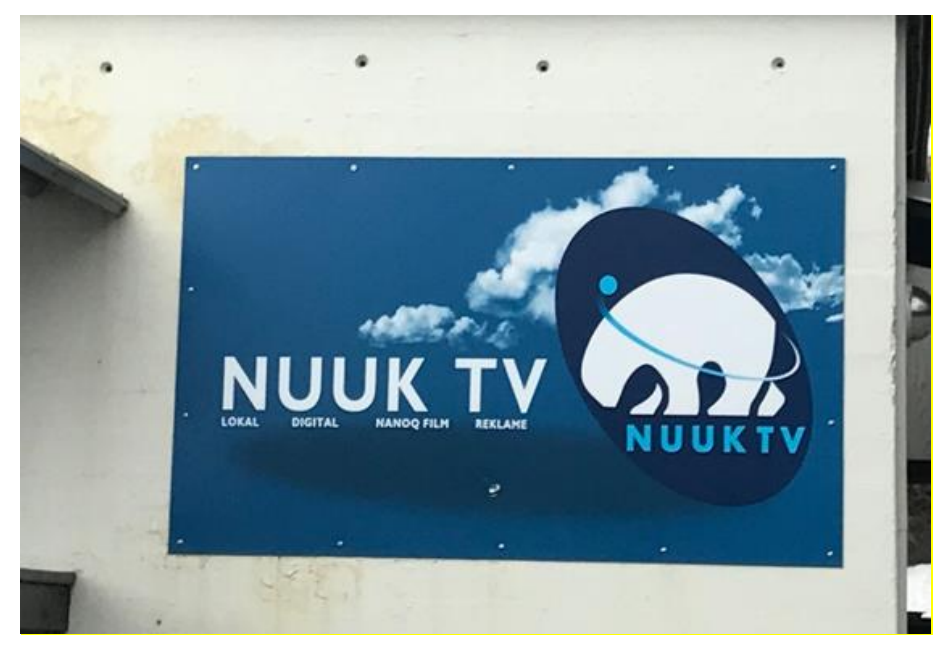

Figure 24. Monolingual Nuuk TV poster

'Nuuk TV: local, digital, Nanoq Film, advertising' (Danish only)

\subsection{English at the centre}

Like Danish, English is most commonly at the periphery in Nuuk, but there are certain contexts in which it is firmly at the centre. These can be divided into three categories: signs for international shipping companies, discussed in 3.3.1, signs for local retail, 
restaurant, and services, discussed in 3.3,2, and text in wall murals and graffiti, discussed in 3.3.3.

\subsubsection{International shipping}

Shipping signs are typically in English rather than in West Greenlandic and/or Danish.

This trend can be seen in Figures 25 and 26. In Figure 25, the government-owned Royal Arctic shipping container appears in English only. Similarly, the shipping company Blue Water (Figure 26) has chosen an English logo with the word Greenland.

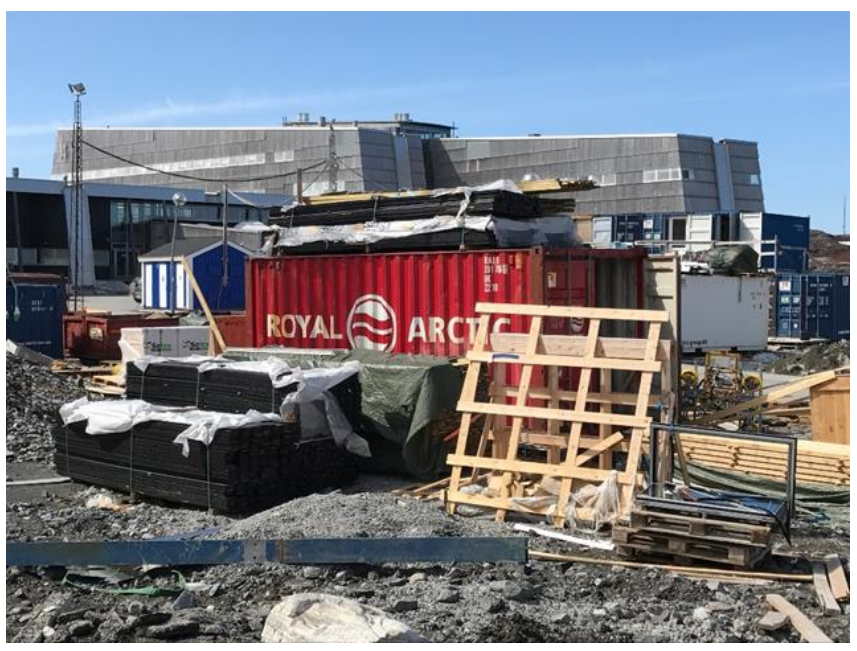

Figure 25. Shipping container

'Royal Arctic' (English only)

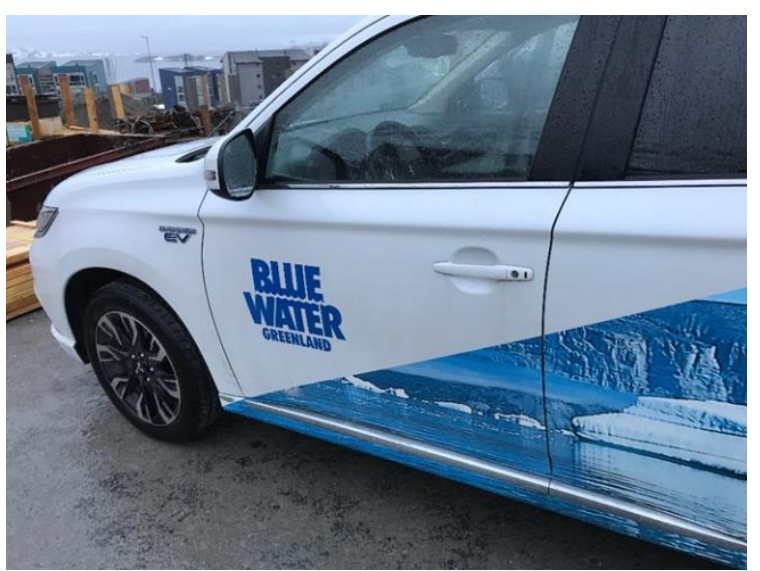


Figure 26. Shipping company logo

'Blue Water, Greenland' (English only)

The use of English as the sole language for international shipping signs and logos is rooted in the fact that shipping in Greenland is an international trade, and as such labelling shipping signs in English has the effect of strengthening the connection to the outside world. With an international target audience, the choice of English has both an informational function (since international readers do not generally understand either West Greenlandic or Danish) and a symbolic one, since use of the international lingua franca has the effect of designating a company as outward-looking and global in reach. This is supported by our interview participants, with F1 commenting that the use of English is 'so that everyone can understand it', and F4 expressing the view that these companies had selected the language in order 'to be international. [...] to promote themselves [...] outside Denmark'.

\subsubsection{Local retail, restaurant, and services signs}

Design shops and other businesses with a largely international clientele are another commercial subcategory where English is prominently at the centre. This trend can be seen in Figure 27, which shows the hoarding of a design store with a monolingual English name and description (as well as the postal code for Nuuk, 3900). A similar case concerns the sign listing the opening hours of the shop Inuk Design in central Nuuk. The opening hours are listed in English first followed by Danish (Figure 28). English is also at the centre as the first language on the sign for an international law office in Nuuk (Figure 29). 


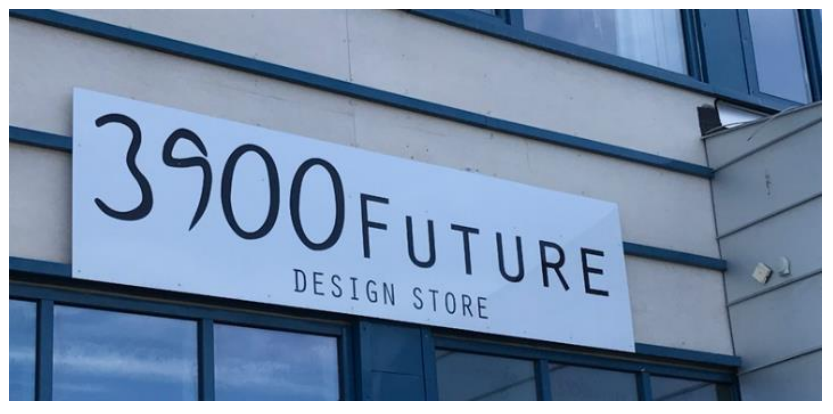

Figure 27. Monolingual design store sign in the centre of Nuuk ‘3900 Future Design Store’ (English only)

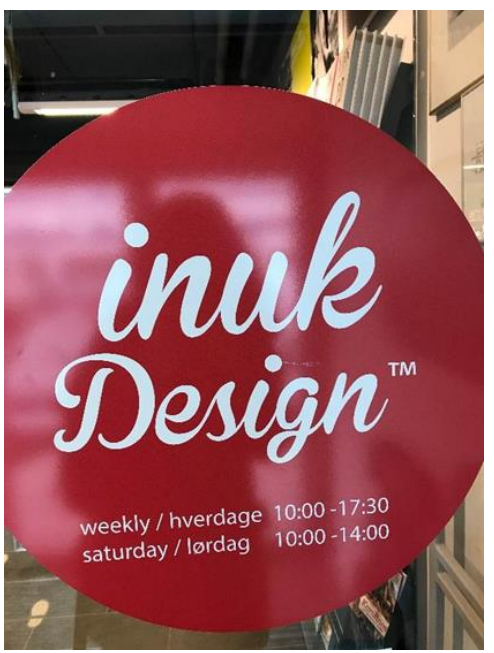

Figure 28. Inuk Design opening hours sign

'weekly’ (English) / 'weekdays' (Danish)

'Saturday’ (English) / 'Saturday’ (Danish)

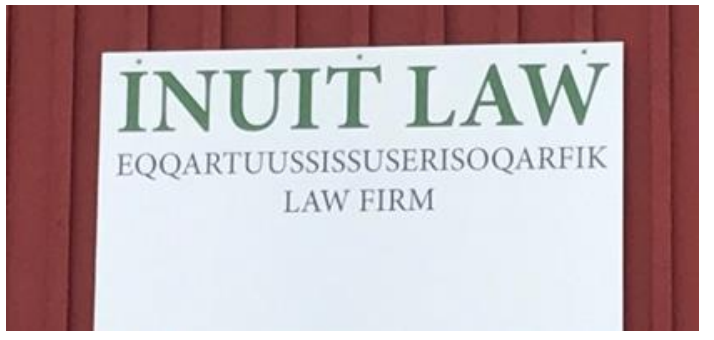


Figure 29. Inuit Law office sign

'Law Firm' (West Greenlandic followed by English)

The use of English in these signs has a twofold function. Some of the clientele is international, so the use of English is partially informational (especially in the case of the opening hours in Figure 28 and the law firm in Figure 29) as it makes the information accessible to customers without knowledge of West Greenlandic or Danish. There is a diachronic element to this trend, with the use of English for touristic purposes set to increase; the provincial government in the Nuuk region plans to invest in more Englishlanguage road signs and signs indicating local attractions for the benefit of international visitors (Kommuneqarfik Sermersooq, 2019a). This prominent use of English in touristic commercial contexts can be contrasted with the use of minority languages as markers of authenticity and exoticization in Finland, as discussed in Kelly-Holmes \& Pietikäinen, 2013 and Pietikäinen, 2013; Switzerland and Catalonia, as discussed in Heller, Pujolar, \& Duchêne, 2014; Wales, as discussed in Coupland, 2012; and Ireland, as discussed in Moriarty, 2014b. However, other parts of the clientele are local, so the prominent use of English on these signs has the effect of creating an association among West Greenlandic speakers of elegance and fashionableness. As F2 observed, English 'sounds cooler, more modern.' Similarly, F4 commented that the use of English in shop names is 'meant to be a bit more luxurious and different. [...] It's meant to be good quality.' It also has associations with high status and professionalism, which is relevant in particular in the case of Inuit Law (Figure 29): F5 remarked that the choice of English in this case makes the business 'appear more professional'. 
The use of English in commercial signs can also be seen in the poster for the planned shopping centre Nuuk Playground shown in Figure 30. The shopping centre is intended to be built in central Nuuk on an empty plot formerly occupied by the infamous housing block called Blok P. Blok P was built in the 1960s during the largescale urbanization project undertaken by the Danish state during that period. The block was regarded as unfit for purpose, and was eventually demolished in 2012.

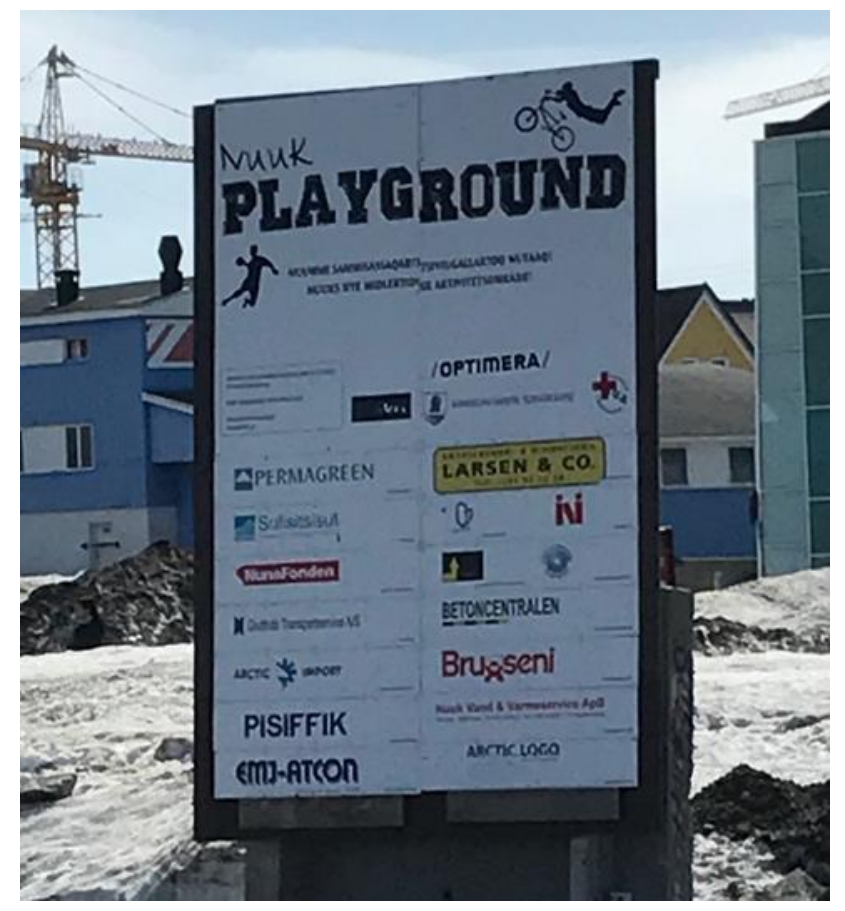

Figure 30. Nuuk Playground shopping centre ${ }^{2}$

'Nuuk Playground' (English)

\footnotetext{
${ }^{2}$ This sign contains the names of various different shops and companies, some of which have been analysed separately in this study (e.g. the supermarkets Brugseni and Pisiffik in 3.1.3 and construction company names such as Betoncentrallen 'Cement Centre' in 3.2.1). Our focus in the present discussion is solely on the name of the entire shopping centre, not on the names of the individual companies which it is expected to house.
} 
The choice of an English word for the name of the planned shopping centre, which is designed for a primarily local market, has the symbolic function of rejuvenating and reinventing the former housing project of the Danish colonial authorities and transforming it into a location with associations of international progressive urbanism. The association of English with this type of contemporary globalism is summarized by F5, who said that 'in my opinion it's because the shop wants to be international and show that it is not only for Greenland or Denmark, they have the expertise in the whole world. We live in a global world where there is more focus on the Arctic.' Moreover, the use of English rather than West Greenlandic and/or Danish also means that the sign has none of the fraught connotations of either the local or the former colonial language: as F5 commented, 'English is a common ground'. The use of English is also reminiscent of the 'aesthetization' and commodification of commercial signs and the use of English in fashion, food, and tourism in Berlin (Papen, 2015).

English is also often at the centre in modern café, restaurant, and bar signs (in contrast to the traditional establishments like Maximut discussed in 3.1.6 above). In this context English sometimes appears on its own. This is illustrated by the Food to Go sign in Figure 31. As in the case of the retail signs mentioned above, our interview participants report that the selection of English in these cases has the effect of signposting the locale as urban and outward looking. In some cases Danish does appear in restaurant and bar signs, as in the pizza house and snack bar sign in Figure 32, yet even in these instances the Danish mirrors English (e.g. snackbar is derived from the English snack bar, while the Danish pizzahus 'pizza house' [which is also used in the names of pizza restaurants in Denmark] echoes the English Pizza Hut). 


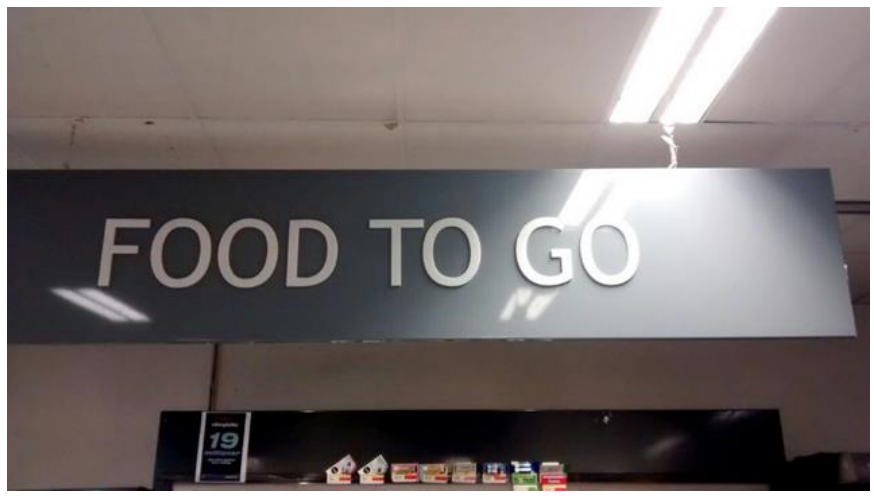

Figure 31. Sign in supermarket

'Food to go' (English)

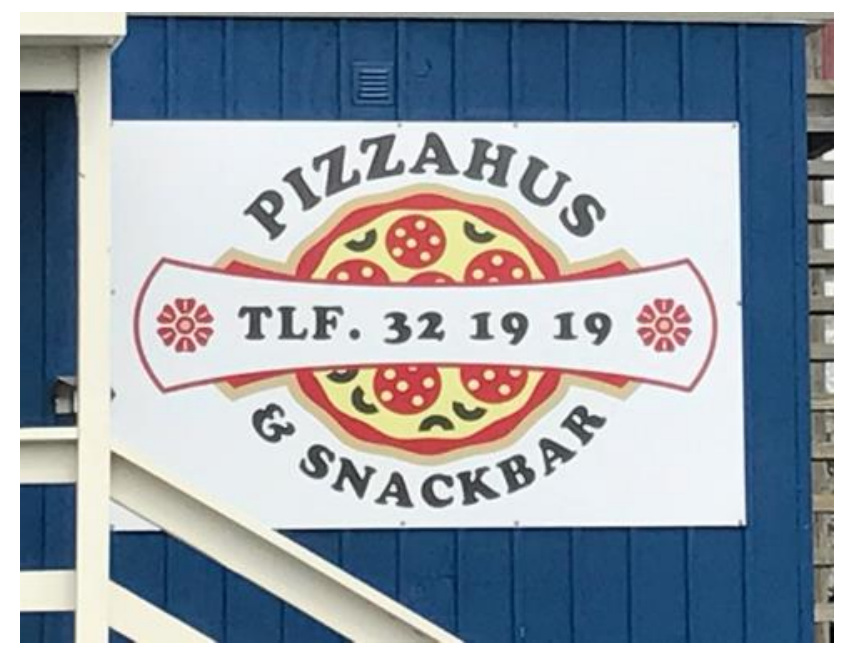

Figure 32. Pizza house and snack bar

'Pizza house and snack bar' (Danish)

The centrality of English in these commercial spaces in Nuuk can fruitfully be compared to that of Tallinn, another smaller European postcolonial capital. In both contexts, one of the functions of English is to push aside the colonial language (Russian in Estonia, Danish in Nuuk); this is supported by our interview participants, who commented that English has neutral connotations, in contrast to Danish (as well as West Greenlandic). However, 
in Tallinn, English has a primarily instrumental role, while Estonian is the language of authenticity, solidarity, and public domain (Soler-Carbonell, 2015), while in Nuuk English has a strongly symbolic role as a language of identification with global culture.

\subsubsection{Wall murals and graffiti}

English is also at the centre in Nuuk wall murals and graffiti. In the case of wall murals, there is a diachronic dimension to this pattern, with a historical shift from West Greenlandic to English. This can be seen by comparing Figures 33 and 34. In Figure 33, an older piece of art on the wall of a social housing block located in central Nuuk, the words are in West Greenlandic only. By contrast, the sign in Figure 34, which appears on a newer social housing block, is monolingual in English. This diachronic shift mirrors the case of road signs (discussed in 3.1.4 above), except that with the road signs, the shift is from Danish to West Greenlandic, whereas here it is from West Greenlandic to English.

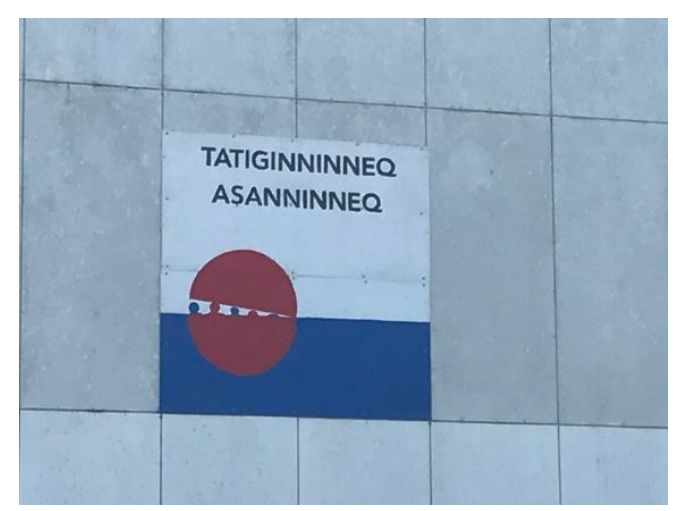

Figure 33. Monolingual sign on social housing block

‘Trust, Love' (West Greenlandic only) 


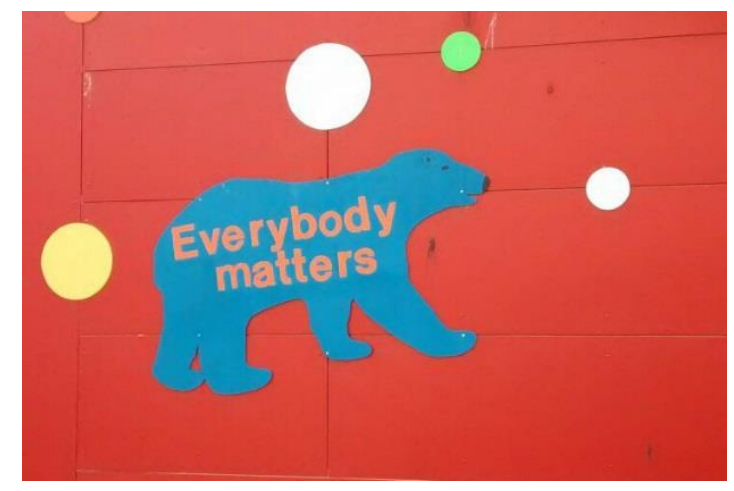

Figure 34. Piece of wall art on a council block

'Everybody matters' (English only)

Both of these murals are targeted primarily at local viewers, as they are not based in touristy locations and are most often seen by residents of these and surrounding buildings. However, the two signs have different symbolic functions. While the monolingual West Greenlandic sign on the older block has the effect of evoking associations with traditional local Greenlandic culture, the contemporary English-language wall art has outwardlooking and progressive associations. Our interview participants thought it unsurprising that recent wall art in Nuuk would feature English-language text because they perceive Nuuk to be more cosmopolitan than other Greenlandic towns. This reflects fact that Nuuk, as Greenland's capital with a population of approximately 17,800 inhabitants, is much bigger than the country's other urban centres: Sisimiut, the second largest city, has only approximately 5,500 inhabitants. As M2 summarized, 'Nuuk is more open, bigger, and more advanced in relation to other towns.'

English is also highly visible and often occupies a central position in informal graffiti written on walls, as in Figures 35, 36, and 37. 


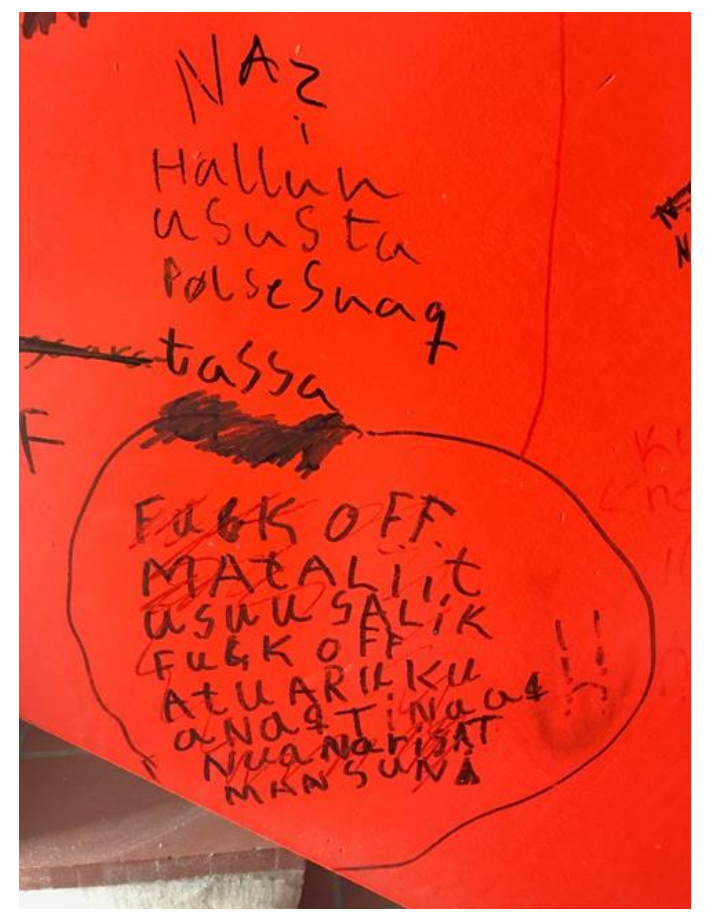

Figure 35. Graffiti inside a block of flats, consisting largely of West Greenlandic- and English-language profanities

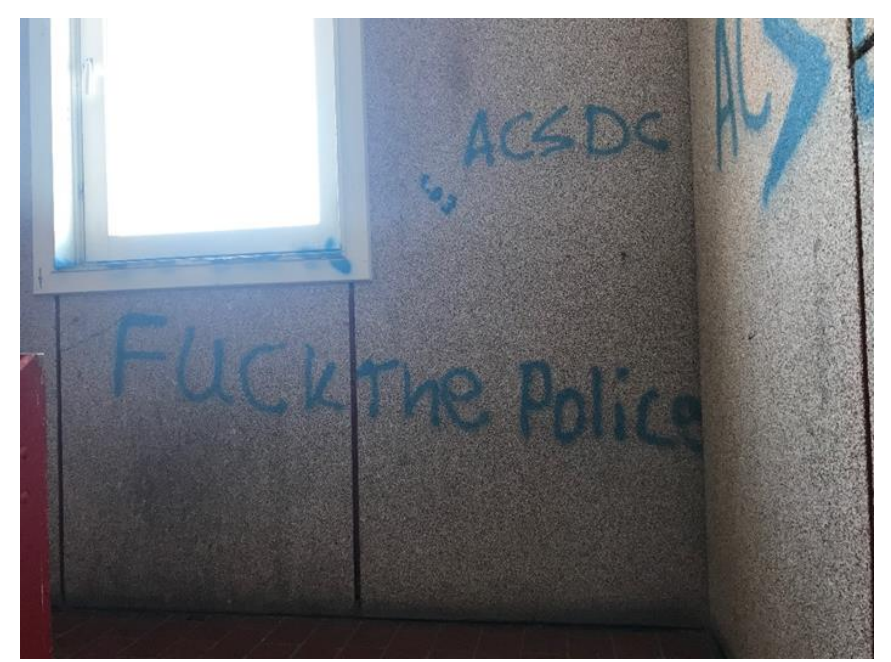

Figure 36. Monolingual graffiti in a block of flats

'Fuck the police' (English only) 


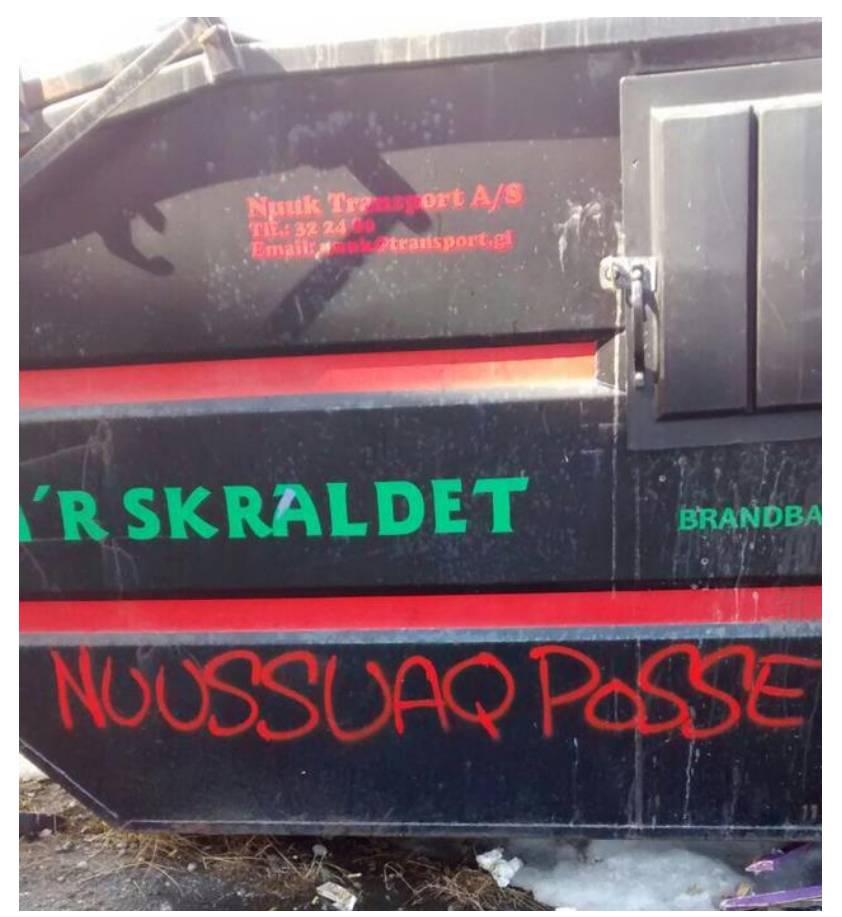

Figure 37. Graffiti in Nuussuaq (suburb of Nuuk) on a skip

'Nuussuaq posse' (English only)

As in the case of the wall art discussed above, these graffiti are viewed primarily by a local audience. The use of English has the symbolic function of signposting the texts as expressions of affiliation with a wider global youth movement. More specifically, in some cases English has the symbolic effect of connecting to a subversive hip hop and gangsta rap culture, as evidenced by the fact that the slogan 'Fuck the Police' featured in Figure 36 is a line from the eponymous song by the Californian gangsta rap/hip-hop group NWA (Bradley \& DuBois, 2010; see especially 237-240). Our interview data support this: 'It's cool, gangsta and it's hip hop. It sounds a bit...if you write in Greenlandic it sounds, eh, old-fashioned, and to be cooler and appear more dangerous. [...] Danish isn't modern enough or big enough. [...] It's international. (F2)'. Since graffiti are situated in a peripheral space and have connotations with lack of power and centrality (cf. Scollon \& 
Scollon, 2003), the selection of English also acts as a counterweight to this lack of centrality by placing the international language of power and prestige at the heart of the location (cf. also Pennycook 2009).

\section{Summary and conclusions}

Our study has examined the linguistic landscape of Nuuk, Greenland as it manifests itself in signs, posters, food labels, and wall art, using the theoretical framework of centre vs. periphery. We have demonstrated that in many different contexts, West Greenlandic is at the centre, usually as the first language in a bilingual or sometimes trilingual sign. This can be seen in both top-down contexts (signs marking state institutions, public information signs, and supermarket signs) and in bottom-up contexts (informal community-produced advertisements and traditional pub signs). In the case of road signs, there is an ongoing diachronic shift whereby West Greenlandic is gradually replacing Danish as the language at the centre in monolingual signs. West Greenlandic is typically at the centre where the primary audience is local, but its function in these cases is not only informational but also symbolic, given that West Greenlandic speakers sometimes prefer to read the Danish version of bilingual signs.

By contrast, Danish is at the centre in fewer contexts, and, in contrast to West Greenlandic, typically has a purely informational rather than symbolic function. Danish appears at the centre in cases where the producers and/or primary audience for the signs is Danish-speaking without knowledge of West Greenlandic, in cases where public health and safety is at stake and Danish can efficiently reach a wider audience than West Greenlandic, and where the content referred to by the signs (in the case of the TV station) is in Danish. 
English is at the centre more frequently than Danish but less widely than West Greenlandic. In contrast to West Greenlandic and Danish, when English is at the centre, it is targeted at both local and international (non-Danish) audiences. In some cases, when the primary audience is international (such as shipping signs), the function of English is largely informational, but in many cases, the primary audience is local (e.g. local retail and restaurant signs), the function is highly symbolic, evoking connotations of internationalism, modernity, luxury, high status, and neutrality.

While our data and findings relate only to the language of written signs and cannot be used to draw conclusions on oral linguistic practices in Nuuk, they do clearly support Møller's (1988: 179) argument that 'bilingualism is a necessity in Greenland'. The evidence drawn from the Nuuk linguistic landscape in the 21 st century could perhaps justify rephrasing this argument to 'trilingualism is a necessity in Greenland', including English as a language of identification and engagement with the international world. The linguistic variety seen within the signs in the different settings demonstrates that, while there is a clear pattern of bringing West Greenlandic to the centre in the majority of contexts, the question of how this trilingualism can best be managed so as to ensure the preeminence of West Greenlandic as the country's chief language in the face of the long colonial legacy of Danish on the one hand, and the rising influence of English on the other, still needs to be negotiated.

We hope that this study may serve as a springboard for further research into the broader sociolinguistic situation in Nuuk and in Greenland more generally, as well to the investigation of specific features of the linguistic landscape in these places. For example, how could an in-depth quantitative study support or complement our initial qualitative findings? How does the actual language use in Nuuk relate to the patterns that can be 
observed on the signs? To what extent is the bilingual practice seen on institutional signs reflected inside these locations, e.g. school buildings, the parliament, the university, the hospital, as well as in the media? What are the common practices regarding the production of bilingual signs, e.g. are they typically written first in Danish and then translated into Greenlandic, or vice versa? Can linguistic influences from the source language be identified in the translated language? How would a large dataset of semi-structured interviews with Greenlandic speakers inform our understanding of language attitudes in Greenland? Investigation of these questions as well as additional detailed sociolinguistic studies of Nuuk and Greenland would be most welcome.

\section{References}

Abousnnouga, G., \& Machin, D. (2010). War monuments and the changing discourses of nation and soldiery. In A. Jaworski, \& C. Thurlow (Eds.), Semiotic landscapes: Language, image, space (pp. 219-240). London: Continuum.

BBC. (2009). Row over 'standard' Hebrew signs. Retrieved on 8 August 2019, from http://news.bbc.co.uk/1/hi/8148089.stm

Ben-Rafael, E., Shohamy, E., Amara, M. H., \& Trumper-Hecht, N. (2006). Linguistic landscape as symbolic construction of the public space: The case of Israel. International Journal of Multilingualism, 3(1), 7-30.

Bigon, L, \& Dahamshe, A. (2014). An anatomy of symbolic power: Israeli road-sign 
policy and the Palestinian minority. Environment and Planning D Society and Space, 32(4), 606-621.

Bjerregaard, P., Curtis, T., \& the Greenland Population Survey. (2002). Cultural change and mental health and Greenland: The association of childhood condition, language, and urbanization with mental health and suicidal thoughts among the Inuit of Greenland. Social Science \& Medicine, 54(1), 33-48.

Blommaert, J. (2007). Sociolinguistics and discourse analysis: Orders of indexicality and polycentricity. Journal of Multicultural Discourses, 2(2), 115-130.

Bradley, A., \& DuBois, A. (2010). NWA. In A. Bradley, \& A. DuBois (Eds.), The anthology of rap (pp. 232-247). New Haven, CT: Yale University Press.

Central Intelligence Agency. (2017). The world fact book 2017, retrieved on 5 May 2019, from https://www.cia.gov/library/publications/the-world-factbook/geos/gl.html.

Coupland, N. (2012). Bilingualism on display: The framing of Welsh and English in Welsh public spaces. Language in Society, 41(1), 1-27.

Emmel, N. (2013). Sampling and choosing cases in qualitative research: A realist approach. Los Angeles: SAGE. 
Frederiksen, K., \& Olsen, C. (2017). Det grønlandske sprog i dag: Rapport over det grønlandske sprog, standpunkt og anbefalinger. Nuuk: Saammaateqatigiinnissamut Isumalioqatigiissitaq.

Gorter, D. (Ed.). (2006). Linguistic landscape: A new approach to multilingualism. Clevedon: Multilingual Matters.

Grenoble, L. (2015). Leveraging language policy to effect change in the Arctic. In M. Jones (Ed.), Policy and planning for endangered languages (pp. 1-17). Cambridge: Cambridge University Press.

Grydehoj, A. (2014). Constructing a centre on the periphery: Urbanization and urban design in the island city of Nuuk, Greenland. Island Studies Journal, 9(2), 205-222.

Grydehoj, A. (2016). Navigating the binaries of island independence and dependence in Greenland: Decolonisation, political culture, and strategic services. Political Geography, $55,102-112$.

Heller, M. (2002). Globalization and commodification of bilingualism in Canada. In D. Block \& D. Cameron (Eds.), Globalization and language teaching (pp. 47-64). London: Routledge.

Heller, M., Pujolar, J., \& Duchêne, A. (2014). Linguistic commodification in tourism. Journal of Sociolinguistics, 18(4), 539-566. 
Jaworski, A. (2015). Globalese: A new visual-linguistic register. Social Semiotics, 25(2), 217-235.

Jaworski, A., \& Thurlow, C. (Eds.). (2010). Semiotic landscapes: Language, image, space. London: Continuum.

Johnson, D. (2017). Linguistic landscaping and the assertion of twenty-first century Māori identity. Linguistic Landscape, 3(1), 1-24.

Kaae, B.C. (2006). Greenland/Kalaallit Nunaat. In G. Baldacchino (Ed.), Extreme tourism: Lessons from the world's cold water islands (pp. 101-112). Amsterdam: Elsevier.

Kallen, J.L. (2010). Changing landscapes: Language, space and policy in the Dublin linguistic landscape. In A. Jaworski, \& C. Thurlow (Eds.) Semiotic landscapes: Language, image, space (pp. 41-58). London: Continuum.

Kelly-Holmes, H. (2013). 'Translation in progress': Centralizing and peripheralizing tensions in the practices of commercial actors in minority language tourist sites. In $\mathrm{H}$. Kelly-Holmes, \& S. Pietikäinen (Eds.), Multilingualism and the periphery (pp. 118-132). Oxford: Oxford University Press. 
Kelly-Holmes, H, \& Pietikäinen, S. (Eds.). 2013. Multilingualism and the periphery. Oxford: Oxford University Press.

Kleemann, N. (Ed.). (2018). Greenland in figures. $15^{\text {th }}$ revised edition. Nuuk: Statistics Greenland.

Kommuneqarfik Sermersooq. (2019). Det bliver nemmere at være turist. 13 March 2019, retrieved on 27 September 2019, from https://sermersooq.gl/da/nyheder/2019/3/13/Detbliver-nemmere-at-vaere-turist

Langgård, P. (2001). Saperasi isumaqaleritsi-Grønlandsk domanevinding. Rapport til Sprogpolitisk referencegruppe prasenteret i november 2001. Nuuk: Oqaasileriffik.

Moriarty, M. (2014a). Languages in motion: Multilingualism and mobility in the linguistic landscape. International Journal of Bilingualism, 18(5), 457-463.

Moriarty, M. (2014b). Contesting language ideologies in the linguistic landscape of an Irish tourist town. International Journal of Bilingualism, 18(5), 464-477.

Møller, A. (1988). Language policy and language planning after the establishment of the home rule in Greenland. Journal of Multilingual \& Multicultural Development, 9(1-2), 177-179.

Nanoq Media (2020). http://nanoqmedia.gl/k1/kanal/, retrieved on 22 March 2020. 
Papen, U. (2015). Signs in cities: The discursive production and commodification of urban spaces. Sociolinguistic Studies, 9(1), 1-26.

Patton, M. Q. (2002). Qualitative research and evaluation methods. $3^{\text {rd }}$ edition. London: SAGE.

Pennycook, A. (2009). Linguistic landscapes and the transgressive semiotics of graffiti. In E. Shohamy, \& D. Gorter (Eds.) Linguistic landscape: Expanding the scenery (pp. 302312). London: Routledge.

Pietikäinen, S. (2013). Heteroglossic authenticity in Sámi heritage tourism. In H. KellyHolmes, \& S. Pietikäinen (Eds.) Multilingualism and the periphery (pp. 77-94). Oxford: Oxford University Press.

Pietikäinen, S. (2014). Spatial interaction in Sámiland: Regulative and transitory chronotopes in the dynamic multilingual landscape of an indigenous Sámi village. International Journal of Bilingualism, 18(5), 478-490.

Pietikäinen, S., Jaffe, A., Kelly-Holmes, H., \& Coupland, N. (2016). Sociolinguistics from the periphery: Small languages in new circumstances. Cambridge: Cambridge University Press. 
Puzey, G. (2008). Planning the linguistic landscape: A comparative study of the use of minority languages in road signage in Norway, Scotland and Italy. Unpublished MA dissertation, University of Edinburgh.

Sermitsiaq. (2012). Se den nye, strengere sproglov. 8 February 2012, retrieved on 27 September 2019, from https://sermitsiaq.ag/node/117951

Scollon, R., \& Scollon, S.W. (2003) Discourses in place: Language in the material world. London: Routledge.

Shohamy, E., \& Gorter, D. (Eds.) (2009). Linguistic landscape: Expanding the scenery. London: Routledge.

Simons, G.F., \& Fennig, C.D. (Eds.). (2017). Ethnologue: Languages of the world, twentieth edition. Dallas, Texas: SIL International. Retrieved on 8 November 2017, from http://www.ethnologue.com

Soler-Carbonell, J. (2015). Tallinn, a multilingual city in the era of globalisation: The challenges facing Estonian as a medium-sized language. In E. Boix-Fuster (Eds.), Urban diversities and language policies in medium-sized linguistic communities (pp. 85-111). Berlin: De Gruyter.

Valijärvi, R.-L., \& Kahn, L., (2018). The semiotic landscape in Nuuk, Greenland. In N. Ostler, V. Ferreira, \& C. Moseley (Eds.), Communities in control: Learning tools and 
strategies for multilingual endangered language communities, Proceedings of FEL XXI (pp. 1-9). London and Leeuwarden: SOAS World Languages Institute and Mercator Research Centre.

Welsh Government. (2018). Traffic signs and road markings, retrieved on 8 September 2019, from https://gov.wales/traffic-signs-and-road-markings

Wright, S. (2004). Language policy and language planning from nationalism to globalisation. London: Palgrave Macmillan. 